\title{
Indicadores de estresse e coping no contexto da educação inclusiva'
}

Kelly Ambrosio Silveirall

Sônia Regina Fiorim Enumo"II

Renata Nascimento Pozzatto ${ }^{\text {IV }}$

Kely Maria Pereira de Paula ${ }^{\text {IV }}$

I- Agradecemos 0 apoio financeiro do $\mathrm{CNPq} / \mathrm{MCTI}$, por meio de bolsa de Iniciação Científica- Proc. n. 508906/2010-5, bolsa de doutorado, bolsa de produtividade em pesquisa, em nível 1B, e auxílio à pesquisa Proc. n. 481483-2009-8.

II- Universidade Federal do Espírito Santo,Vitória, ES, Brasil.

Contato: kellysilveira.psicologia@gmail.com

III- Pontifícia Universidade Católica de Campinas, Campinas, SP; Brasil.

Contato: sonia.enumo@gmail.com;

IV- Universidade Federal do Espírito Santo,

\section{Resumo}

A escola tem sido o principal meio de educação para alunos com necessidades educativas especiais (NEE), graças às políticas inclusivas. Mas as dificuldades vivenciadas na implementação de tais políticas podem contribuir para o desenvolvimento de estresse entre docentes. Tendo isso em vista, no presente artigo procurou-se identificar os estressores e os níveis de estresse docente e analisar variáveis sóciodemográficas, pessoais, do trabalho e dos alunos, de acordo com a presença de estresse. Dezenove professoras de classes de $1^{\circ}, 2^{\circ}$ e $3^{\circ}$ ano do Ensino Fundamental de escolas públicas da cidade de Vitória/ES, regentes de classes com alunos com NEE, responderam ao Inventário de Sintomas de Stress para adultos de Lipp, a um questionário com variáveis de interesse e a seis escalas de estressores e de enfrentamento (coping), especialmente traduzidas e adaptadas para o presente estudo. A grande quantidade de alunos e seus problemas comportamentais foram os estressores mais frequentes. Especificamente com relação à educação inclusiva, destacaram-se a sobrecarga de serviço e a percepção de pouca preocupação governamental em fornecer subsídios para o trabalho. Todavia, cabe ressaltar que a inclusão de alunos com NEE foi um fator menos citado, podendo não ser a variável central para o estresse, uma vez que os docentes com estresse apontaram mais frequentemente a seguinte causa: a percepção de incompreensão pública frente ao trabalho docente. A partir dessa constatação, sugerem-se intervenções para a promoção do bem-estar entre os professores.

\section{Palavras-chave}

Estresse - Enfrentamento - Professores - Educação inclusiva. 


\section{Indicators of stress and coping in the context of inclusive education'}

Kelly Ambrosio Silveira"

Sônia Regina Fiorim Enumo"II

Renata Nascimento Pozzattoiv

Kely Maria Pereira de Paulaiv
I- We acknowledge the financial support of $\mathrm{CNPq} / \mathrm{MCTI}$, by means of scientific initiation fellowship number 508906/2010-5, a doctoral fellowship, a research productivity fellowship level 1B, and research support number 481483-2009-8.

II- Universidade Federal do Espírito Santo,Vitória, ES, Brasil.

Contact: kellysilveira.psicologia@gmail.com III-Pontifícia Universidade Católica de Campinas, Campinas, SP; Brasil. Contact: sonia.enumo@gmail.com; IV- Universidade Federal do Espírito Santo, Vitória, ES, Brasil. Contacts: renatapozzatto@ gmail.com; kely.paula@ufes.br

\section{Abstract}

Thanks to inclusive policies, school has been the main means of education for pupils with special educational needs (SEN). But the difficulties experienced in the implementation of such policies may contribute to the development of stress among teachers. Keeping this in view, this study has sought to identify stressors and levels of teacher stress and examine sociodemographic, personal, work and student variables, according to the presence of stress. Nineteen teachers of classes of $1^{\text {st }}, 2^{\text {nd }}$ and $3^{\text {rd }}$ grades of primary education in public schools in Vitória city, Espirito Santo state, Brazil, working with classes with students with SEN, responded to Lipp's Inventory of Stress Symptoms for Adults, a questionnaire with variables of interest and six scales of stressors and coping, translated and adapted especially for this study. The large number of students and their behavioral problems were the most frequent stressors. With regard to inclusive education, the main results were work overload and the perception that the government is little concerned with providing support for work. However, it is noteworthy that the inclusion of pupils with SEN was a less cited factor and may not, thus, be the central variable for stress. Actually, teachers with stress identified more often the following cause: the perception of the public misunderstanding of the teaching work. Based on this finding, we suggest interventions to promote well-being among teachers.

\section{Keywords}

Stress - Coping - Teachers - Inclusive education. 


\section{Introdução}

As políticas nacionais de atendimento educacional especial têm afırmado a escola como o principal agente para os processos de ensino e aprendizagem dos alunos com necessidades educativas especiais - NEE (BRASIL, 2008a, 2008b). Essas políticas propõem a reformulação do ensino, com a recepção de alunos com condições diferenciadas de desenvolvimento e a oferta de recursos físicos, didáticos e interacionais adaptados às NEE, tendo como foco o trabalho com a diversidade (MANTOAN, 2003).

Desde a Declaração de Salamanca (UNESCO, 1994), a definição do conceito de NEE tornou-se mais abrangente, passando a contemplar alunos cujas necessidades envolvam deficiências ou dificuldades de aprendizagem, com a manifestação de desvantagem ou sobredotação, problemas de conduta ou de ordem emocional, além de situação de risco psicossocial ou pertencimento a minorias. Com isso, em seus princípios, a educação inclusiva passou a contemplar a diversidade entre os alunos e a adequar meios e recursos para os processos educacionais.

0 professor, nesse contexto, é tradicionalmente reconhecido como facilitador dos processos de aprendizagem, mediando as experiências escolares (RODRIGUEZ; BELLANCA, 2007). Entretanto, parece haver descontentamento com relação à maneira como o processo de inclusão está sendo implantado, por ser muitas vezes dissociado de investimentos em adaptações físicas das escolas, na aquisição de materiais específicos às necessidades dos alunos e na formação dos profissionais. Em consequência, o ensino de alunos com diferentes níveis de desenvolvimento na sala de aula regular pode ser um fator estressor para o trabalho docente.

0 estresse, entendido como o resultado de respostas fisiológicas e psicológicas a eventos internos e externos (COMPAS, 2006), tem suscitado o desenvolvimento de pesquisas na área docente (GOULART JÚNIOR; LIPP, 2008; MARTINS, 2005; POCINHO; CAPELO,
2009). Contudo, muitas pesquisas das últimas décadas ainda têm considerado os professores como avaliadores das condições de estresse de alunos e familiares, ao invés de tomá-los como sujeitos de pesquisa sobre as suas condições laborais estressoras (WITTER, 2003). Além disso, o estresse tem sido causa recorrente de afastamentos do trabalho (GASPARINI; BARRETO; ASSUNÇÃO, 2005), o que abre a possibilidade de novos focos de análise, como os estressores do contexto escolar inclusivo e as estratégias de enfrentamento (EE) utilizadas pelos professores. É o que investigaremos no presente trabalho.

\section{Definições de estresse e de estratégias de enfrentamento e suas aplicações no contexto escolar}

0 estresse pode ser entendido como um conjunto de reações psicológicas e/ou físicas produzidas no confronto com uma situação desafiadora ao sujeito. Apresenta-se em quatro estágios gradativos, que variam do estado de alerta até o de exaustão, esta considerada a fase patológica, com importante desequilíbrio interior, depressão e produtividade nula (LIPP, 2002). 0 estresse pode ser também caracterizado por uma experiência emocional negativa que, no caso do professor, pode ser acionada pela percepção de que sua situação de trabalho constitui uma ameaça à sua autoestima e ao seu bem-estar (KYRIACOU; SUTCLIFFE, 1978), a depender da interação entre as características individuais e a percepção das exigências presentes.

Considerando a experiência de estresse, sabe-se que, caso seja cumulativo, ele pode gerar mais consequências adversas do que eventos isolados. Além disso, a restrição de escolhas, o pouco controle e a grande responsabilidade, presentes também no trabalho docente, podem ser estressores significativos (ALDWIN, 2007).

Já o estresse em sua vertente ocupacional é entendido como o resultado da interação entre condições laborais e individuais, de modo que 
as exigências criadas ultrapassam a capacidade de lidar com elas (GOMES; PEREIRA, 2008). Porém, nem sempre a experiência de estresse é, em si, danosa. Na perspectiva de Pocinho e Capelo (2009), se uma situação profissional encarada como exigente for bem sucedida, o estresse possibilita a adaptação e a confiança. Ao contrário, pode haver aumento do estresse, ligado à percepção de dificuldade na adaptação às exigências.

Em casos extremos de estresse em professores, pode ocorrer ainda a Síndrome de Burnout (BENEVIDES-PEREIRA et al., 2003), um tipo de estresse ocupacional que tende a acometer profıssionais envolvidos em atividades de cuidado e atenção direta e altamente emocional (MASLACH; JACKSON, 1981). É resultado de uma experiência subjetiva que altera hábitos, satisfação, autocontrole, concentração na sala de aula e que acentua reações emocionais a acontecimentos cotidianos (RITA; PATRÃO; SAMPAIO, 2010) e pode prejudicar os processos interativos (BENEVIDES-PEREIRA et al., 2008).

Nesse contexto, considerando que as pessoas têm um papel ativo no processo de enfrentamento a situações adversas, como se lida com o estresse é mais importante que a simples exposição a ele (ALDWIN, 2007). 0 conceito de coping ou estratégias de enfrentamento (EE) inclui respostas voluntárias ao estresse, a partir de esforços conscientes para a regulação da emoção, cognição, comportamento e ambiente (COMPAS, 2006). As EE do estresse, mesmo sendo consideradas adaptativas, podem transformar uma condição em um fator de risco ou conferir proteção (SKINNER et al., 2003). Sousa et al. (2009) complementam esse tema em revisão sobre estresse ocupacional, burnout e coping, na qual apresentaram o coping como variável mediadora entre a avaliação dos estressores e as respostas de estresse (explica como essas respostas ocorrem) e como variável moderadora entre o estresse ocupacional e o burnout (aumenta a força do estresse).

Considera-se também que o bem-estar no trabalho pode ser sustentado nos sentimentos de otimismo e autoeficácia, mobilizadores da crença de controle e modificação do ambiente (BANDURA, 1997). A autoeficácia aumenta no professor a percepção de possibilidade de mudança no comportamento do aluno e em seu próprio comportamento (ALMOG; SHECHTMAN, 2007) e exerce um papel importante no modo de cada pessoa enfrentar os desafios que a ela se apresentem (POCINHO; CAPELO, 2009).

A literatura internacional a respeito do estresse e EE tem apontado para a existência de diferentes estressores do ambiente escolar. Entre os principais, destacam-se: lidar com a classe e manter a disciplina, aplicar as tarefas, organizar grupos de trabalho, ajudar crianças com problemas comportamentais e preparar recursos para lições (RIEG; PAQUETTE; CHEN, 2007), lidar com incidentes envolvendo comportamento desafiador (KELLY et al., 2007) e indisciplina (LHOSPITAL; GREGORY, 2009), vivenciar a falta de suporte diante de problemas comportamentais dos alunos (ZURLO; PÉS; COOPER, 2007), suportar o excesso de trabalho e a falta de tempo (ANTONIOU; POLYCHRONI; KOTRONI, 2009; BETORET; ARTIGA, 2010), articular-se com relação às diferenças de desenvolvimento e motivação dos alunos e às políticas educacionais (POCINHO; CAPELO, 2009), e lidar com a pressão exercida pelos pais (STOEBER; RENNERT, 2008).

No Brasil, os estressores mais comumente encontrados são o desinteresse da família em acompanhar a trajetória educacional dos filhos, a infraestrutura inadequada da escola, os problemas de indisciplina e o desnível entre os alunos, a grande demanda e desvalorização profissional e a falta de trabalho em equipe (RODRIGUES et al., 2005).

Considerando tais fatores e a própria necessidade de efetivação das políticas inclusivas no Brasil, acredita-se que as atuais adequações ao modelo inclusivo de ensino também possam ser um desafio. Constata-se, na literatura, a falta de preparo (GUARINELLO et al., 2006), devido a falhas na formação acadêmica (VALLE; 
GUEDES, 2003) e profissional (FONTES, 2009; NAUJORKS, 2002) dos professores. Dificuldades na articulação de programas e de políticas (FERREIRA, 2007) e na orientação oferecida por outros profissionais (MAIA-PINTO; FLEITH, 2002; SILVEIRA; NEVES, 2006) também são apontadas como falhas na implementação de programas de inclusão.

A dissociação entre o trabalho prescrito e o trabalho real em educação inclusiva pode levar à angústia (DUEK; NAUJORKS, 2008), ao desconforto acerca do processo educacional (MONTEIRO; MANZINI, 2008; RIOS; NOVAES, 2009), à sobrecarga e a sintomas de ansiedade e depressão (LIMA et al., 2003). A falta de apoio e de conhecimento sobre como lidar nesse contexto também tem colocado o docente no papel de professor-cuidador (MELO; FERREIRA, 2009). Trata-se de uma postura tipicamente assistencialista, que isola o aluno e não motiva seu crescimento (ALBUQUERQUE, 2008; SODRÉ; PLETSCH; BRAUN, 2003). A esse respeito, Naujorks (2002) aponta que, mesmo com formação adequada, pode haver dificuldades no trabalho com os alunos devido a experiências internas, decorrentes de crenças e valores pessoais, os quais, estando em conflito com a realidade que se apresenta, podem acentuar o estresse.

0 presente estudo, assim, enfatizou a avaliação do estresse, das características sociodemográficas, pessoais, do trabalho e dos alunos, a fim de fornecer dados que subsidiem intervenções de caráter preventivo (MURTA; LAROS; TRÓCCOLI, 2005) ou interventivo (LAUGAA; RASCLE; BRUCHON-SCHWEITZER, 2008) como possibilidade de prevenção ao aumento dos sintomas de estresse e burnout em professores.

\section{Objetivos}

Este trabalho pretendeu, de modo geral, avaliar os níveis de estresse e os estressores percebidos frente ao trabalho, em consideração a fatores específicos à educação inclusiva e a outros fatores estressores gerais para a atividade docente em professores do Ensino Fundamental da rede pública do município de Vitória (ES), que atuam em classes com a inclusão de pelo menos um aluno com alguma necessidade educativa especial. Os objetivos específicos desta pesquisa foram:

a) avaliar a presença de estresse nesses professores;

b) identificar os principais estressores percebidos por esses professores, considerando aqueles que se apresentam como gerais e específicos ao contexto de educação inclusiva;

c) identificar variáveis sóciodemográficas, pessoais e do trabalho desses professores e de seus alunos, associadas a altos níveis de estresse.

\section{Método}

Para atender aos objetivos propostos, a pesquisa contou com delineamento descritivo para identificar os estressores e os níveis de estresse. Também realizou a análise de um grupo estático, para casos de altos e baixos níveis de estresse (KANTOWITZ; ROEDIGER; ELMES, 2006; SELLTIZ; WRIGHTSMAN; COOK, 1981).

\section{Participantes e local de coleta}

Participaram 19 professoras de $1^{\circ}$ (8), $2^{\circ}$ (6) e $3^{\circ}$ ano (5) do Ensino Fundamental, que tinham alunos com algum tipo de necessidade educativa especial (NEE) em suas salas de aula, situadas em quatro escolas públicas municipais de Vitória. Tais escolas estão localizadas em bairros de classe média do município com indices de qualidade urbana semelhantes.

0 critério utilizado para a coleta foi abranger professores de uma mesma região do município para garantir maior consistência nos dados quanto à presença dos estressores ambientais percebidos. As participantes foram contatadas durante o expediente nas escolas. A coleta de dados foi realizada nas dependências das escolas, em horários pertinentes à rotina de trabalho dos professores, com anuência dos 
diretores e pedagogos, de modo a não causar danos à rotina escolar ou à saúde das participantes.

\section{Instrumentos e materiais}

1) Questionário de caracterização dos participantes, com os seguintes itens: idade, sexo e modalidade de ensino em que atua, tempo de serviço e quantidade de alunos em sala, incluindo a quantidade de alunos com alguma necessidade educativa especial percebida. Tal instrumento foi desenvolvido para a presente pesquisa;

2) Escala de Estressores do Contexto Escolar: conta com 20 itens acerca de estressores gerais ligados ao trabalho docente, pontuados de 1 a 5 quanto ao grau de estresse percebido para cada item. Esse instrumento é parte do Questionnaire Taiwanese Primary School Teachers' Stress and Coping Strategies (KYRIACOU; CHIEN, 2004). Os itens foram traduzidos e adaptados transculturalmente seguindo as orientações da literatura da área (KLEIN; PUTNAN; LINHARES, 2009).

3) Inventário de Indicadores de Stress ligados ao Trabalho no Ensino Inclusivo (NAUJORKS, 2002, em adaptação do Stress Faculty Index de GMELCH; LOVRICH; WILKE, 1984, para professores da Educação Inclusiva (EI) no país): contém 25 itens que representam problemas e insatisfações ligados ao exercício da docência no contexto inclusivo. Os itens são pontuados caso o participante concorde em referir-se à sua percepção atual sobre o trabalho;

4) Escala de Vulnerabilidade ao Estresse no Trabalho - EVENT (SISTO et al., 2007): a partir de 40 itens, avalia o quanto as circunstâncias do cotidiano do trabalho influenciam a conduta da pessoa, a ponto de caracterizar certa fragilidade para o desenvolvimento de estresse laboral. Avalia a vulnerabilidade ao estresse a partir de três fatores: fator 1 - clima e funcionamento organizacional; fator 2 - pressão no trabalho; e fator 3 - infraestrutura e rotina;

5) Inventário de Sintomas de Stress para Adultos de Lipp - ISSL (LIPP, 2000): identifica a presença de sintomas de estresse, os tipos de sintomas existentes, sejam eles físicos ou psicológicos, a presença e a fase do estresse que se manifesta - Alerta, Resistência, Quase exaustão ou Exaustão, a partir de 37 itens de natureza somática e 19 de natureza psicológica. A escala é dividida em três partes, referentes aos sintomas físicos e psíquicos sentidos nas últimas 24 horas, na última semana e no último mês;

6) Escala de Coping para Professores: com 25 itens sobre comportamentos de coping ou enfrentamento. É parte do Questionnaire Taiwanese Primary School Teachers' Stress and Coping Strategies (KYRIACOU; CHIEN, 2004). Esse instrumento também foi traduzido e adaptado transculturalmente. Durante o preenchimento, o participante é requisitado a apontar a frequência para a eficácia percebida de cada comportamento na redução do estresse e a frequência com que manifesta cada comportamento listado, a partir de escala que varia de 1 a 5 ;

7) Escala de Satisfação do Professor: conta com 5 itens pontuados de 1 a 5 acerca do grau de concordância quanto aos itens ligados a indicadores de satisfação no trabalho docente. Os itens foram adaptados a partir da Teacher Satisfaction Scale (HO; AU, 2006);

8) Escala de Autoeficácia do Professor no desenvolvimento de atividades: apresenta 4 itens adaptados da Norwegian Teacher Self-Efficacy Scale (SKAALVIC; SKAALVIC, 2010). Os itens referem-se a indicadores de eficácia percebida pelo participante no desenvolvimento de atividades do trabalho, especialmente referentes à adaptação de instrução às necessidades individuais dos alunos.

Ressalta-se que o uso dos instrumentos descritos deu-se em consequência à inexistência de um instrumento específico que pudesse fornecer as informações necessárias, tendo em vista os objetivos aqui propostos. Como a literatura também ainda não sugere de forma consistente uma bateria de instrumentos avaliativos para a coleta de dados pessoais e laborais ligados a estressores e ao estresse, foi montada a presente lista de instrumentos, especialmente 
formulada para o desenvolvimento desta pesquisa. Ao todo, foram coletadas as variáveis:

a) sociodemográficas: idade, sexo, estado civil, número de filhos, estresse familiar percebido e total de horas diárias de lazer;

b) do trabalho: série escolar em que atua, anos de experiência em salas regulares inclusivas, anos na instituição, anos de serviço, horas diárias de planejamento em casa, tipo de vínculo e número de turnos em que trabalha;

c) dos alunos: quantidade de alunos em sala, quantidade de alunos com NEE em sala, quantidade de crianças com laudo médico, quantidade de crianças que frequentam sala de atendimento educacional especializado, presença de estagiário em sala; e

d) pessoais: satisfação com o trabalho, autoeficácia percebida no trabalho, percepção de estressores, comportamentos de enfrentamento ao estresse, percepção de itens ligados à vulnerabilidade ao estresse no trabalho, fatores estressores ligados à Educação Inclusiva e sintomatologia do estresse.

Para a análise dos dados, foi utilizado o software SPSS - Statistical Package for the Social Sciences ${ }^{\circledR}$, na versão 18.

\section{Procedimento}

Antes de a coleta ser iniciada, foram mantidos os procedimentos para a tradução e adaptação transcultural de instrumentos ainda não adaptados ou comercializados, de modo a preservar a semântica e o escopo teórico subjacente aos mesmos (KLEIN; PUTNAN; LINHARES, 2009). Após aprovação da pesquisa junto ao Comitê de Ética em Pesquisas da UFES (n. 264-11), foi estabelecido contato com a Secretaria Municipal de Educação, a fim de se obter anuência para inserção nas escolas e para o processo de coleta de dados. Em seguida, as instituições escolares da região foram contatadas.

Após o consentimento para a participação da coleta, foram oferecidos os protocolos e as instruções diretamente pelos pesquisadores. Ao final da coleta, foi realizada devolutiva a cada participante. A pesquisa não implicou riscos à saúde das participantes, nem custos ou exposição das mesmas. Todas assinaram o Termo de Consentimento para a Pesquisa. A coleta foi realizada durante os períodos de intervalo, com o objetivo de não trazer prejuízo ao andamento das atividades programadas.

\section{Resultados}

As 19 professoras que participaram da coleta tinham, em média, 44,1 anos ( $\mathrm{DP}=7,1)$, sendo a maioria casada (52,6\%). Lecionavam no $1^{\circ}$ ano $(36,8 \%), 2^{\circ}$ ano $(26,3 \%)$ e $3^{\circ}$ ano $(15,8 \%)$ como regentes de classe e $10,3 \%$ delas tinham disciplinas nessas séries escolares. A maioria trabalhava em dois turnos (73,7\%) e em duas escolas (57,9\%), com uma média de 22,3 anos de serviço $(\mathrm{DP}=7,3)$, sendo a maior parte delas $(78,9 \%)$ efetiva em pelo menos um turno. Estavam trabalhando na instituição há 7,3 anos $(\mathrm{DP}=7,9)$ e a experiência em classes com a inclusão de alunos com NEE era de 13,5 anos $(\mathrm{DP}=8,1)$. Apenas 26,3\% tinham estagiário na sala de aula. Havia, em média, 1,78 alunos com NEE por professora ( $\mathrm{DP}=0,98)$.

As NEE apontadas pelas participantes foram: deficiência mental (10), TDAH (8), deficiência visual (5), altas habilidades (3), dislexia (3), deficiência física (2), deficiência múltipla (1), transtorno global do desenvolvimento (1) e deficiência auditiva (1).

Um total de 10 professoras (52,63\%) apresentou estresse. Dessas, quase a totalidade (nove) encontrava-se na fase de resistência e uma estava na fase de quase exaustão. A sintomatologia foi tanto física quanto psicológica, porém, houve predomínio de sintomas físicos (70\%).

\section{Estressores percebidos acerca do trabalho docente}

Foram destacados os 25\% dos itens mais e menos pontuados da lista de estressores. Os mais pontuados, em ordem decrescente das médias obtidas, foram: grande quantidade de alunos na sala; problemas comportamentais 
dos alunos; atitude pública de incompreensão sobre a carga de trabalho do professor; falta de motivação dos alunos; e falta de recursos suficientes para o ensino. Os itens menos pontuados, em ordem decrescente das médias obtidas, foram: competição entre colegas de trabalho; dificuldade para auxiliar alunos em atividades extras; envolvimento em atividades para formação continuada; problemas para auxiliar os alunos no desenvolvimento de tarefas escolares; e estranhamento ao ser observado por colegas, estagiários, supervisores ou pais (Tabela1).

Verificou-se que a permanência de crianças com NEE em sala de aula, em si, não foi um fator de estresse pontuado com alta frequência entre as participantes. Contudo, fatores indiretamente ligados à sobrecarga e às atividades escolares no contexto inclusivo foram largamente apontados, tais como a falta de recursos para o ensino e a grande quantidade de alunos por sala de aula.

Tabela 1 - Estressores apontados pelas professoras de classes inclusivas ( $N=19)$

\begin{tabular}{|c|c|c|}
\hline Estressores & $M^{*}$ & $\mathrm{DP} *$ \\
\hline Grande quantidade de alunos na sala & 4,10 & 1,24 \\
\hline Problemas comportamentais dos alunos & 3,94 & 1,31 \\
\hline Atitude pública de incompreensão sobre a carga de trabalho do professor & 3,84 & 1,01 \\
\hline Falta de motivação dos alunos & 3,84 & 1,34 \\
\hline Falta de recursos suficientes para o ensino & 3,52 & 1,38 \\
\hline Atitudes pobres dos alunos frente às tarefas & 3,47 & 1,17 \\
\hline Poucos recursos para trabalho & 3,26 & 1,69 \\
\hline Estilo de gerenciamento dos superiores & 3,10 & 1,14 \\
\hline Comunicação com pais & 3,00 & 1,45 \\
\hline Mudanças constantes nas políticas educacionais & 2,89 & 1,32 \\
\hline Excesso de conteúdo a ser lecionado & 2,78 & 1,13 \\
\hline Trabalhar com conteúdos não ligados à expectativa, preparo, habilidade & 2,73 & 1,32 \\
\hline Pouco tempo de intervalo & 2,72 & 1,01 \\
\hline Trabalho administrativo adicional & 2,57 & 1,07 \\
\hline Alunos com necessidades educativas especiais na sala & 2,52 & 1,17 \\
\hline Competição entre colegas de trabalho & 2,47 & 1,21 \\
\hline Auxiliar alunos em atividades extras & 2,36 & 1,42 \\
\hline Envolvimento em atividades para formação continuada & 2,15 & 1,16 \\
\hline Auxiliar no desenvolvimento de diversas tarefas extras da escola & 2,10 & 1,32 \\
\hline Ser observado por colegas, estagiários, supervisores ou pais & 1,73 & 0,93 \\
\hline
\end{tabular}

Fonte: dados da pesquisa

${ }^{*} \mathrm{M}=$ Média; DP = Desvio padrão 


\section{Estressores percebidos acerca do trabalho no contexto da educação inclusiva}

Considerando a Educação Inclusiva, o estressor mais frequente a partir do Inventário de Indicadores de Estresse ligados ao Trabalho no Ensino Inclusivo (NAUJORKS, 2002) foi a sobrecarga de serviço, seguida da percepção de pouca preocupação em fornecer aos professores subsídios necessários ao trabalho junto à diversidade. Os estressores frequentes em mais de 50\% da amostra encontram-se na Tabela 2.

Tabela 2 - Indicadores mais frequentes de estresse ligados ao trabalho no ensino inclusivo $(\mathrm{N}=19)$

\begin{tabular}{l:l}
\multicolumn{1}{c}{ Indicadores } & $\%$ \\
\hline "Há uma sobrecarga de serviço docente que impede o & 63 \\
aperfeiçoamento, principalmente em relação a esta proposta." & 63 \\
\hline "Sinto que não existe uma preocupação efetiva em fornecer & 63 \\
subsídios aos professores para trabalhar com a diversidade." & 63 \\
\hline $\begin{array}{l}\text { "Sinto que esta proposta tem um conteúdo muito mais } \\
\text { político do que pedagógico." }\end{array}$ & 63 \\
\hline "Meu salário não é adequado para cobrir minhas & 53 \\
necessidades pessoais e familiares." & \\
\hline
\end{tabular}

Fonte: dados da pesquisa

\section{Características sociodemográficas, pessoais e do trabalho dos professores e de seus alunos, de acordo com a presença de estresse}

Para a análise das variáveis sociodemográficas e pessoais, dos alunos e do trabalho, de acordo com a presença de estresse, realizou-se um teste de diferença entre grupos para amostras não paramétricas (Mann Whitney-U), considerando duas condições: com estresse versus sem estresse. Não houve diferença significativa para a quantidade de alunos com NEE para os grupos de participantes com e sem estresse (Tabela 3).

Também não houve diferenças para as variáveis sociodemográficas, do trabalho e dos alunos, no que tange à presença ou não de estresse. Foram observadas diferenças em variáveis pessoais ligadas à percepção de alguns estressores, à satisfação com o trabalho e a algumas EE (Tabela 3).

Entre as professoras com estresse, houve maior pontuação para os escores totais, especialmente para os estressores ligados à grande quantidade de alunos na classe, à

Tabela 3 - Diferenças significativas na percepção de estressores entre professoras de classes inclusivas com e sem estresse

\begin{tabular}{|c|c|c|c|c|c|}
\hline \multirow{2}{*}{$\begin{array}{l}\text { Condições de stress } \\
\text { Variáveis analisadas }\end{array}$} & \multicolumn{2}{|c|}{ Sem estresse } & \multicolumn{2}{|c|}{ Estresse } & \multirow[b]{2}{*}{${ }^{*} \mathrm{p}$-valor } \\
\hline & Rank & $M^{*}$ & Rank & $M^{*}$ & \\
\hline Estressor - Grande quantidade de alunos na classe $(f)$ & 6,67 & 3,33 & 13,00 & 4,80 & 0,00 \\
\hline Estressor - Atitude pública de incompreensão sobre carga de trabalho $(f)$ & 6,22 & 3,11 & 13,40 & 4,50 & 0,00 \\
\hline Estressor - Ser observado por colegas, estagiários, supervisores ou pais ( $f$ ) & 7,17 & 1,22 & 12,55 & 2,20 & 0,02 \\
\hline Estressor (escore médio) & 6,94 & 2,55 & 12,90 & 3,32 & 0,02 \\
\hline Estressor Educação Inclusiva (soma) & 7,33 & 5,22 & 12,40 & 8,70 & 0,04 \\
\hline Vulnerabilidade estresse, fator infraestrutura/rotina $(f)$ & 6,19 & 5,00 & 10,81 & 9,37 & 0,05 \\
\hline Coping percebido- Assegurar-se de que entende o conteúdo $(f)$ & 12,83 & 4,77 & 7,45 & 3,90 & 0,02 \\
\hline Coping percebido- Tentar conhecer mais os alunos em suas especificidades, como indivíduos ( $f$ ) & 12,56 & 4,55 & 7,70 & 3,80 & 0,04 \\
\hline Coping manifesto- Assegurar-se de que entende o conteúdo ( $f$ ) & 12,83 & 4,66 & 7,45 & 3,80 & 0,02 \\
\hline Coping manifesto- Enxergar o lado cômico da situação ( $f$ ) & 12,83 & 4,22 & 7,45 & 3,10 & 0,02 \\
\hline Coping manifesto- Ter uma vida pessoal saudável $(f)$ & 12,61 & 3,66 & 7,65 & 2,70 & 0,04 \\
\hline Coping manifesto- Ficar só $(f)$ & 13,72 & 3,11 & 6,65 & 1,50 & 0,00 \\
\hline Satisfação no trabalho (escore médio) & 12,83 & 3,73 & 7,45 & 3,00 & 0,03 \\
\hline
\end{tabular}

${ }^{*} p=$ significância da diferença entre grupos. Valores $\leq 0,05$ são considerados significativos pelo teste de Mann Whitnney-U. $M=$ Média. $(f)=$ frequência. Fonte: dados da pesquisa 
atitude pública de incompreensão sobre a carga de trabalho e ao fato de ser observado por colegas, estagiários e supervisores ou pelos pais dos alunos.

Além disso, houve maior frequência de estressores ligados à Educação Inclusiva e maior média para o fator de vulnerabilidade para o estresse ligado à infraestrutura e à rotina. Com isso, é possivel que professores com estresse possam experimentar maior percepção de sobrecarga de trabalho proveniente das interrelações entre as atividades realizadas e a oferta de materiais e recursos para o desenvolvimento do trabalho.

Professoras sem estresse, por outro lado, apresentaram maior sensação de satisfação com o trabalho. Apresentaram também uma percepção mais aguçada a respeito da efetividade dos comportamentos de enfrentamento do estresse, ligados a manter-se seguro sobre o conteúdo a ser ensinado e a tentar conhecer os alunos em suas especificidades. Esse grupo demonstrou ainda maior percepção de efetividade dos comportamentos ligados ao planejamento, à busca de informações e à reestruturação cognitiva frente aos desafios, para a redução do estresse.

Assegurar-se de que entende o conteúdo, ficar só, ter uma vida saudável e enxergar o lado cômico da situação foram comportamentos mais praticados entre aqueles sem estresse, em comparação ao grupo com estresse. Esses comportamentos também são ligados à busca de informações, à reestruturação cognitiva frente aos desafios e à busca de relaxamento.

\section{Discussão}

0 presente trabalho pretendeu avaliar os níveis de estresse e os estressores percebidos em professoras do Ensino Fundamental da rede pública do município de Vitória/ES que atuam em salas com a inclusão de pelo menos um aluno com alguma NEE. Foram levadas em consideção variáveis pessoais, do trabalho e dos alunos.

Uma parcela significativa da amostra apresentou quadro de estresse ${ }_{\text {๖ }}$ confirmando os dados da literatura que afirmam a docência como categoria vulnerável a tal condição (GOULART JÚNIOR; LIPP, 2008; MARTINS, 2005; POCINHO; CAPELO, 2009). 0 nível de estresse presente em nove das 10 professoras com estresse foi o de resistência, caracterizado por uma tentativa automática de lidar com as situações de estresse para manter a saúde (LIPP, 2000), fase também recorrente entre os docentes (MARTINS, 2007).

Os sintomas apresentados foram, em sua maioria, físicos. Assim como em outras regiões ou redes de ensino, a maioria trabalhava em dois turnos e em duas escolas. Considerando toda a amostra, pouco mais de um quarto contava com estagiário em sala de aula, apesar de, em média, haver quase dois alunos com alguma NEE por professora.

Os estressores apontados com maior frequência, considerando toda a amostra, incluiam a grande quantidade de alunos na sala e os seus problemas comportamentais, a atitude pública de incompreensão sobre o trabalho do professor, a falta de motivação dos alunos e a falta de recursos suficientes para o ensino. Pesquisas nacionais (FERREIRA, 2007; RODRIGUES et al., 2005) e internacionais (POCINHO; CAPELO, 2009; RIEG; PAQUETTE; CHEN, 2007; ZURLO; PÉS; COOPER, 2007) confirmam a presença de tais estressores.

A permanência de crianças com NEE, em si, não foi um fator de estresse pontuado com alta frequência entre as professoras, podendo não ser uma variável determinante para o estresse. Possivelmente, a presença de tais alunos não seja um fator de maior desafio ou ameaça ao bem-estar no trabalho, em comparação à percepção significativa de outros problemas, como a falta de materiais e recursos, além da pouca valorização do trabalho realizado.

Esses fatores, em consequência, podem interpor-se à experiência do trabalho educacional com enfoque inclusivo. Assim, o que mais parece afligir esses docentes é a falta de preocupação das políticas educacionais ou da sua efetivação no que tange ao fornecimento 
de subsídios para o trabalho com a diversidade de alunos, assim como apontado por Ferreira (2007), Maia-Pinto e Fleith (2002) e Silveira e Neves (2006). Talvez, por causa disso, entre as professoras com estresse tenha havido maior frequência para fatores ligados à Educação Inclusiva, como a baixa percepção de efetividade das políticas educacionais e a percepção de pouco comprometimento com a proposta, entre outros.

Os resultados apontaram alguns fatores que poderiam influenciar no contexto da sala inclusiva, tais como a quantidade de alunos em sala e a falta de recursos. Os fatores de vulnerabilidade ao estresse ligados à infraestrutura e à rotina, que constam na Escala de Vulnerabilidade ao Estresse no Trabalho (EVENT), foram mais presentes entre aquelas professoras com estresse e complementam o quadro observado a partir dos outros instrumentos de coleta de dados.

Ser observado por colegas, estagiários, supervisores ou pais de alunos foi o fator menos pontuado como estressor pelas professoras. Porém, esse fator foi indicado com maior frequência por aqueles que apresentaram estresse, assim com a percepção da incompreensão pública de seu trabalho. Tendo em vista esses resultados, é possível que o professor com maiores níveis de estresse possa sentir-se mais afligido pela observação de terceiros quando o trabalho não é desempenhado nas condições ideais, ou quando seu trabalho não é tão eficaz como gostaria que fosse.

Nesse caso, o raciocínio inverso também poderia ser aplicado, ou seja, aqueles professores que experimentam maior descontentamento em relação à efetivação das políticas públicas voltadas ao ensino em salas inclusivas, as quais deveriam abarcar a diversidade de características e de necessidades educativas dos alunos, poderiam sentir maior constrangimento diante da inadequação da prática realizada, ou da contradição manifesta diariamente entre o processo educacional idealizado e aquele vislumbrado de modo deficiente. Tensões cotidianas poderiam, assim, levar a sinais mais expressivos de estresse (RITA; PATRÃO; SAMPAIO, 2010).

$\mathrm{Na}$ tentativa de compreender as diferenças nos níveis de estresse e na percepção de estressores no modelo inclusivo, de acordo com variáveis pessoais e do trabalho, serão apresentados a seguir os dados obtidos sobre as estratégias de enfrentamento apontadas pelos professores.

Assegurar-se de que entende o conteúdo a ser ensinado e tentar conhecer mais os alunos em suas especificidades foram comportamentos avaliados pelos professores sem estresse como mais eficazes no enfrentamento das dificuldades que podem surgir em sala, em comparação àqueles com nível significativo de estresse. Os professores sem estresse apresentaram também uma maior sensação de satisfação com o trabalho, o que também pode ser um fator de proteção (CARLOTTO, 2002).

Sabe-se que as EE utilizadas para lidar com as situações estressantes, tanto na escola quanto em sua vida pessoal, além de modular as reações de estresse, podem influenciar a forma como os professores lidarão com os alunos em sala e na administração dos recursos didáticos (ANTONIOU; POLYCHRONI; KOTRONI, 2009; CARMONA et al., 2008). Deve-se considerar também que as EE podem sofrer influências de inúmeras outras variáveis, como o tempo de serviço, local e condições de trabalho, gênero, condições sociodemográficas (idade, estado civil e número de filhos), além da autoeficácia, entre outras variáveis (GOMES; PEREIRA, 2008; POCINHO; CAPELO, 2009). Nem todos esses modelos foram testados na presente pesquisa, de modo que estudos futuros poderão complementar a compreensão do processo de enfrentamento ao contexto da Educação Inclusiva e seus possíveis impactos, considerando as variáveis sugeridas.

Os dados obtidos deflagram análises complexas acerca da experiência em salas inclusivas e do seu enfrentamento, análises essas que não deverão se encerrar nesta discussão, pois a experiência do ensino inclusivo parece ser subjacente ao processo de desenvolvimento do trabalho dos professores e merece maior 
atenção entre os pesquisadores. Contudo, mesmo considerando as limitações presentes no método empregado no presente artigo, tais como o número reduzido de participantes $\mathrm{e}$ as consequentes técnicas de análise de dados, que se tornam mais imprecisas, é possível fazer alguns questionamentos.

Considerando as diferenças obtidas entre os grupos com e sem estresse, é possivel que, entre aqueles professores com menos estresse, haja maior adaptação às características do trabalho, tendo em vista a maior expressividade nas respostas ligadas às estratégias de enfrentamento. Diante disso, é possível indagar: aqueles professores sem níveis significativos de estresse teriam desenvolvido estratégias adaptativas às características da educação real, repleta de desafios, de diversidade e de diferenças individuais?

Entende-se por educação real aquela que ultrapassa as barreiras da idealização construída durante o processo formativo, que instrumentaliza o profissional diante da falta de recursos, de materiais, de maior conhecimento e que o motiva na busca de estratégias voltadas à sua superação e ao desenvolvimento de comportamentos favorecedores do trabalho com crianças reais, em salas reais.

Talvez manter o foco nos problemas do cotidiano percebidos ao longo do exercício das atribuições laborais que, por vezes, ocorrem em condições diferentes daquelas idealizadas, possa acentuar as tensões e a experiência de estresse. Com isso, ressalta-se a incompreensão pública frente à carga de trabalho do professor encontrada nos resultados, percebida de modo expressivo entre as participantes.

Com a maior compreensão de seu trabalho educativo e inclusivo pela comunidade, a partir do envolvimento mais efetivo dos alunos e dos pais na vida escolar de seus filhos e de uma política de valorização do trabalho, é possível que haja impacto na satisfação e na percepção de eficácia nas atividades realizadas, com reforçamento de comportamentos adaptativos ao bem-estar e ao processo de ensino-aprendizagem.
Cabe também ressaltar as condições que comprometem essa percepção pelo professor, como a sensação de ser incompreendido, a pouca colaboração com o trabalho docente e a falta de envolvimento em sala de aula. Trata-se de aspectos que podem colaborar para o aumento do risco de estresse, uma vez que o professor pode sentir que necessita exercitar trabalho de grande responsabilidade sem dispor de autonomia suficiente para a produção de resultados acadêmicos e comportamentais nos alunos (ALDWIN, 2007). É possível que a persistência de estressores que coloquem em risco a percepção de autonomia e responsabilidade possa levar a atitudes de esquiva frente ao trabalho, a fim de se buscar a restauração do self e o equilíbrio. Tal postura, todavia, pode comprometer os relacionamentos estabelecidos em sala de aula com os alunos.

É inegável que, para evitar o estresse e seus danos recorrentes, não seja necessária apenas uma mudança de atitude do professor frente à educação inclusiva, modalidade que intensifica a diversidade na escola, com desafios e limitações que requerem constantes tentativas de adaptação. Obviamente, o investimento em recursos e em formação deve acompanhar de forma imprescindivel esta proposta. Cabe lembrar, então, que o desenvolvimento das atribuições laborais do professor, acima de tudo, necessita ser subsidiado por políticas de incentivo salarial, material e formativo, direcionadas tanto ao profissional quanto ao contexto escolar e que favoreçam os processos de saúde e a qualidade das experiências de aprendizagem criadas.

Há a necessidade de uma investigação mais ampla acerca da utilização das EE e seu impacto na redução do estresse, tendo em vista os diferentes estressores que atuam no contexto escolar. $\mathrm{Na}$ amostra avaliada, houve mais comportamentos ligados ao planejamento, busca de informações ou reestruturação cognitiva diante de desafios entre as professoras sem estresse. É possível, com isso, que a manifestação desses comportamentos possa favorecer a autoeficácia percebida e ter efeito protetor contra o estresse docente. 
Pode-se pensar também que a percepção de autoeficácia no trabalho, em si, apesar de poder ocasionar um maior esforço para mudança das condições estressoras, na medida em que se acredita ser capaz de fazê-lo (ALMOG; SHECHTMAN, 2007), pode não ser capaz de proteger o profissional do estresse, caso a presença e a percepção dos estressores seja $\mathrm{m}$ intensas, de modo a comprometer a relação entre a autonomia e as responsabilidades ligadas ao trabalho (ALDWIN, 2007).

Desse modo, se acompanhado de investimentos materiais, formativos e em recursos humanos, o sentimento de autoeficácia pode contribuir para o bem-estar do professor e sua satisfação. Isso torna o ambiente de trabalho mais saudável, também para os alunos, na medida em que possibilita exercer a crença de controle e de modificação do ambiente (BANDURA, 1997) favorecendo a manifestação de EE mais adaptativas (POCINHO; CAPELO, 2009).

É necessário destacar que, embora pequena, a amostra por nós analisada foi significativa para a região onde a pesquisa foi realizada, de modo que novas investigações com amostras maiores e mais abrangentes podem vir a complementar os dados encontrados. Seria também interessante acompanhar o cotidiano dos profissionais, suas per- cepções sobre o trabalho em salas inclusivas e o relacionamento manifesto com os alunos ao longo do ano, para melhor observar os efeitos longitudinais da docência no contexto inclusivo sobre as percepções construídas, com comportamentos exibidos e os níveis de estresse apresentados.

Os resultados obtidos ajudam a confirmar a presença do estresse entre as professoras, além de destacar os principais estressores percebidos no desenvolvimento do trabalho. Destacam a presença de fatores estressantes complementares à educação inclusiva que podem ampliar a experiência de estresse, apesar da presença, em si, de alunos com NEE não ter sido apontada como fator significativo de estresse.

Portanto, são interessantes intervenções preventivas voltadas ao desenvolvimento de treino para a manifestação assertiva das competências pessoais adquiridas durante a formação acadêmica, profissional ou pessoal, considerando a realidade do trabalho e seus desafios. Nesse sentido, é útil a organização de intervenções que construam, junto com os docentes, formas que facilitem a administração de situações estressoras a partir de treinamento em recursos de coping mais adequados ao contexto escolar.

\section{Referências}

ALBUQUERQUE, Ednea Rodrigues. Decifra-me ou te devoro: os alunos com necessidade educacionais especiais nas representações sociais de seus professores. In: ALMEIDA, Maria Amelia; MENDES, Enicéia Gonçalves; HAYSHI, Maria Cristina Piumbato Innocentini. (Orgs.). Temas em educação especial: múltiplos olhares. Araraquara: Junqueira \& Marin. Brasília: CAPES/PROESP, 2008. p. $202-212$.

ALDWIN, Carolyn M. Stress, coping, and development: an integrative perspective. New York: Guilford Press, 2007.

ALMOG, Orit; SHECHTMAN, Zipora. Teachers' democratic and efficacy beliefs and styles of coping with behavioural problems of pupils with special needs. European Journal of Special Needs Education, Philadelphia, v. 22, n. 2, p. 115-129, maio 2007.

ANTONIOU, Alexander-Stamatios; POLYCHRONI, Fotini; KOTRONI, Christina. Working with students with special educational needs in Greece: teachers' stressors and coping strategies. International Journal of Special Education, Vancouver, v. 24, n. 1, p. 100-111, 2009.

BANDURA, Albert. Self-efficacy: the exercise of control. New York: W. H. Freeman, 1997.

BENEVIDES-PEREIRA, Ana Maria T. et al. Sintomas de estresse em educadores brasileiros. Aletheia, Porto Alegre, v. 17, p. 63-72, 2003. 
BENEVIDES-PEREIRA, Ana Maria T. et al. 0 trabalho docente e o burnout: um estudo em professores paranaenses. In: CONGRESSO NACIONAL DE EDUCAÇÃO DA PUCPR EDUCERE, 8, 2008, Paraná, Anais do VIII congresso nacional de educação. Curitiba: Pontifícia Universidade Católica do Paraná, 2008. p. 4870-4884.

BETORET, F. Doménech; ARTIGA, A. Gómez. Barriers perceived by teachers at work, coping strategies, self-efficacy and burnout. The Spanish Journal of Psychology, Madrid, v. 13, n. 2, p. 637-654, 2010.

BRASIL. Declaração de Salamanca e enquadramento da acção na área das necessidades educativas especiais. Brasília: UNESCO, 1994.

Política nacional de educação especial na perspectiva da educação inclusiva. Brasília: MEC/SEESP, Ministério da Educação, 2008a.

. Decreto-lei n 6.571, de 17 de setembro de 2008. Diário Oficial da União. Brasília, 18 set. 2008b, p. 26.

CARLOTTO, Mary Sandra. Síndrome de burnoute satisfação no trabalho: um estudo com professores universitários. In: BENEVIDESPEREIRA, Ana Maria T. (Org.). Burnout: quando o trabalho ameaça o bem-estar do trabalhador. São Paulo: Casa do Psicólogo, 2002. p. 187-212.

CARMONA, Carmen et al. Do social comparison and coping styles play a role in the development of burnout? Cross-sectional and longitudinal findings. Journal of Occupational and Organizational Psychology, v. 79, p. 85-99, 2006.

COMPAS, Bruce E. Psychobiological processes of stress and coping: implications for resilience in children and adolescents. Comments on the papers of Romeo \& McEwen and Fisher et al. Annals of the New York Academy of Sciences, v. 1094, p. 226-234, 2006.

DUEK, Viviane Preichardt; NAUJORKS, Maria Inês. Inclusão e autoconceito: reflexões sobre a formação de professores. In: ALMEIDA, Maria Amélia; MENDES, Enicéia Gonçalves; HAYASHI, Maria Cristina Piumbato Innocentini. (Orgs.). Temas em educação especial: múltiplos olhares. Araraquara: Junqueira \& Marin; Brasília: CAPES/PROESP, 2008. p. 176-183.

FERREIRA, Maria Elisa Caputo. 0 enigma da inclusão: das intenções às práticas pedagógicas. Educação e Pesquisa, São Paulo, v. 33, n. 3, p. 543-560, dez. 2007.

FONTES, Rejane de Souza. Ensino colaborativo: uma proposta de educação inclusiva. Araraquara: Junqueira \& Marin, 2009.

GASPARINI, Sandra Maria; BARRETO, Sandhi Maria; ASSUNÇÃO, Ada Ávila. 0 professor, as condições de trabalho e os efeitos sobre sua saúde. Educação e Pesquisa, São Paulo, v. 1, n. 2, p. 189-199, 2005.

GMELCH, Walter H.; LOVRICH, Nicholas P.; WILKE, Phyllis Kay. (1984). Sources of stress in academy: a national perspective. Research in Higher Education, v. 20, n. 4, p. 477-490, 1984

GOMES, Rosa Maria Silva; PEREIRA, Anabela Maria Sousa. Estratégias de coping em educadores de infância portugueses. Psicologia Escolar e Educacional, Campinas, v. 12, n. 2, p. 319-326, 2008.

GOULART JUNIOR, Edward; LIPP, Marilda Emmanuel Novaes. Stress entre professoras do ensino fundamental de escolas públicas estaduais. Psicologia em Estudo, Maringá, v. 13, n. 4, p. 847-857, 2008.

GUARINELLO, Ana Cristina et al. A inserção do aluno surdo no ensino regular: visão de um grupo de professores do Estado do Paraná. Revista Brasileira de Educação Especial, Marília, v. 12, n. 3, p. 317-330, 2006.

HO, Chung-Lim.; AU, Wing-Tung. Teaching Satisfaction Scale: measuring job satisfaction of teachers. Educational and Psychological Measurement, v. 66, n. 1, p. 172-185, 2006.

KANTOWITZ, Barry H.; ROEDIGER, Henry L.; ELMES, David G. Psicologia experimental: psicologia para compreender a pesquisa em psicologia. São Paulo: Thomson, 2006.

KELLY, Áine et al. Challenging behaviour: principals' experience of stress and perception of the effects of challenging behaviour on staff in special schools in Ireland. European Journal of Special Needs Education, v. 22, n. 22, p. 161-181, 2007.

KLEIN, Vivian Caroline; PUTNAM, Samuel P.; LINHARES, Maria Beatriz Martins. Assessment of temperament in children: translation of instruments to Portuguese (Brazil) Language. Interamerican Journal of Psychology, Porto Alegre, v. 43, n. 3, p. 442-447, 2009.

KYRIACOU, Chris; CHIEN, Pei-Yu. Teacher stress in Taiwanese primary schools. Journal of Educational Enquiry, v. 5, n. 2, p. 86-104, 2004. 
KYRIACOU, Chris; SUTCLIFFE, J. Michael. Teacher stress: prevalence, sources and symptoms. British Journal of Educational Psychology, v. 48, n. 2, p. 159-167, 1978.

LAUGAA, Didier; RASCLE, N.; BRUCHON-SCHWEITZER, Marilou. Stress and burnout among French elementary school teachers: a transactional approach. Revue Européenne de Psychologie Appliquée, v. 58, n. 4, p. 241-251, 2008.

LHOSPITAL, Ann Shargo; GREGORY, Anne. Changes in teacher stress through participation in pre-referral intervention teams. Psychology in the Schools, v. 46, n. 10, p. 1098-1112, 2009.

LIMA, F. B. et al. Humanização do posto de trabalho docente: uma alternativa ergonômica na inclusão educacional. In: NUNES SOBRINHO, Francisco de Paula. (Org.). Inclusão educacional: pesquisas e interfaces. Rio de Janeiro: Livre Expressão, 2003. p. 79-97.

LIPP, Marilda Emmanuel Novaes. Manual do inventário de sintomas de stress para adultos. São Paulo, SP: Casa do Psicólogo, 2000. 0 estresse do professor. Campinas: Papirus, 2002

MAIA-PINTO, Renata Rodrigues; FLEITH, Denise de Souza. Percepção de professores sobre alunos superdotados. Estudos em Psicologia, Campinas, v. 19, n. 1, p. 78-90, 2002.

MANTOAN, Maria Teresa Eglér. Inclusão escolar: o que é? Por quê? Como fazer? São Paulo: Moderna, 2003.

MARTINS, Maria das Graças Teles. Sintomas de stress em professores das primeiras séries do ensino fundamental: um estudo exploratório. 2005. 193 p. Dissertação (Mestrado em Ciências da Educação) - Universidade Lusófona de Humanidades e Tecnologias, Lisboa, 2005.

Sintomas de stress em professores brasileiros. Revista Lusófona de Educação, Lisboa, n. 10, p. 109-128, 2007.

MASLACH, Christina; JACKSON, Susan E. The measurement of experienced burnout. Journal of Occuppational Behavior, v. 2, p. 99-113, 1981.

MELO, Francisco Ricardo Lins Vieira de; FERREIRA, Caline Cristine de Araújo. 0 cuidar do aluno com deficiência física na educação infantil sob a ótica das professoras. Revista Brasileira de Educação Especial, Marília, v. 15, n. 1, p. 121-140, 2009.

MONTEIRO, Ana Paula Húngaro; MANZINI, Eduardo José. Mudanças nas concepç̃es do professor do ensino fundamental em relação à inclusão após a entrada de alunos com deficiência em sua classe. Revista Brasileira de Educação Especial, Marília, v. 14, n. 1, p. 35-52, 2008.

MURTA, Sheila Giardini; LAROS, Jacob Arie; TROCCOLI, Bartholomeu Torres. Manejo de estresse ocupacional na perspectiva da área de avaliação de programas. Estudos de Psicologia, Natal, v. 10, n. 2, p. 167-176, 2005.

NAUJORKS, Maria Inês. Stress e inclusão: indicadores de stress em professores frente à inclusão de alunos com necessidades educacionais especiais. Educação Especial, Santa Maria, 20, 117-125, 2002.

POCINHO, Margarida; CAPELO, Maria Regina. Vulnerabilidade ao estresse, estratégias de coping e autoeficácia em professores portugueses. Educação e Pesquisa, São Paulo, v. 35, n. 2, p. 351-367, 2009.

RIEG, Sue A.; PAQUETTE, Kelli R.; CHEN, Yijie. Coping with stress: an investigation of novice teachers' stressors in the elementary classroom. Education, v. 128, n. 2, p. 211-226, 2007.

RIOS, Noemi Vieira de Freitas; NOVAES, Beatriz Cavalcanti de A Caiuby. 0 processo de inclusão de crianças com deficiência auditiva na escola regular: vivências de professores. Revista Brasileira de Educação Especial, Marília, v. 15, n. 1, p. 81-98, 2009.

RITA, Joana Santos; PATRÃO, Ivone Alexandra Martins; SAMPAIO, Daniel. Burnout, estresse profissional e ajustamento emocional em professores portugueses do ensino básico e secundário. In: SIMPÓSIO NACIONAL DE INVESTIGAÇÃO EM PSICOLOGIA, 7., 2010, Lisboa, Actas do VII Simpósio Nacional de Investigação em Psicologia da Universidade do Minho. Lisboa: Universidade do Minho, 2010. p. 1151-1160.

RODRIGUES, M. L. et al. Estresse ocupacional: um estudo com professores das redes pública e privada de ensino. Revista da Sociedade de Psicologia do Triângulo Mineiro, Uberlândia, v. 9, n. 1, p. 37-44, 2005.

RODRIGUEZ, Eleanor Renee; BELLANCA, James. What is it about me you can't teach? An instructional guide for the urban educator. Thousand Oaks: Corwin, 2007. 
SELLTIZ, C. A.; WRIGHTSMAN, L.; COOK, S. W. Métodos de pesquisa nas relações sociais: delineamentos de pesquisa. São Paulo: E.P.U., 1981

SILVEIRA, Flávia Furtado; NEVES, Marisa Maria Brito da Justa. Inclusão escolar de crianças com deficiência múltipla: concepções de pais e professores. Psicologia: Teoria e Pesquisa, Brasília, v. 22, n. 1, p. 79-86, 2006.

SISTO, Fermino Fernandes et al. Escala de Vulnerabilidade ao Estresse no Trabalho - EVENT. São Paulo: Vetor, 2007.

SKAALVIK, Einar M.; SKAALVIK, Sidsel. Teacher self-efficacy and teacher burnout: a study of relations. Teaching and Teacher Education, v. 26, n. 4, p. 1059-1069, 2010

SKINNER, Ellen A. et al. Searching for the structure of coping: a review and critique of category systems for classifying ways of coping. Psychological Bulletin, v. 129, n. 2, p. 216-269, 2003.

SODRÉ, J.; PLETSCH, Márcia Denise; BRAUM, P. A. Formação inicial e continuada de recursos humanos para a prática docente frente à educação inclusiva. In: NUNES SOBRINHO, Francisco de P. (Org.) Inclusão educacional: presquisa e interfaces. Rio de Janeiro: Livre Expressão, 2003.

SOUSA, Ivone Félix de et al. Estresse ocupacional, coping e burnout. Revista Estudos, Goiânia, v. 36, n. 1/2, p. 57-74, 2009.

STOEBER, J.; RENNERT, D. Perfectionism in school teachers: relations with stress appraisals, coping styles, and burnout. Anxiety, Estresse, \& Coping, v. 21, v. 1, p. 37-53, 2008.

VALLE, M. H. F.; GUEDES, T. R. Habilidades e competências do professor frente à inclusão. In: NUNES SOBRINHO, Francisco de Paula. (Org.). Inclusão educacional: pesquisa e interfaces. Rio de Janeiro: Livre Expressão, 2003. p. 42-61.

WITTER, Geraldina Porto. Professor-estresse: análise de produção científica. Psicologia Escolar e Educacional, Campinas, v. 7 , n. 1, p. 1-17, 2003

ZURLO, Maria Clelia; PES, Daniela; COOPER, Cary L. Stress in teaching: a study of occupational stress and it's determinants among Italian school teachers. Stress and Health, v. 23, p. 231-241, 2007.

Recebido em: 06.09.2012

Aprovado em: 18.02.2013

Kelly Ambrosio Silveira é doutoranda em Psicologia pelo Programa de Pós-Graduação em Psicologia da Universidade Federal do Espírito Santo e bolsista de doutorado do CNPq/MCTI.

Sônia Regina Fiorim Enumo é doutora em Psicologia pela Universidade de São Paulo; Docente do Programa de PósGraduação em Psicologia da Pontifícia Universidade Católica de Campinas, e orientadora no Programa de Pós-Graduação em Psicologia da Universidade Federal do Espírito Santo e bolsista de produtividade em pesquisa em nível 1B do CNPq/MCTI.

Renata Nascimento Pozzatto é aluna do curso de Graduação em Psicologia da Universidade Federal do Espírito Santo, bolsista de Iniciação Científica do PIBIC/CNPq.

Kely Maria Pereira de Paula é psicóloga e professora do Departamento de Psicologia Social e do Desenvolvimento e do Programa de Pós-Graduação em Psicologia da Universidade Federal do Espírito Santo, doutora em Psicologia pela Universidade Federal do Espírito Santo. 


\section{Interações comunicativas entre uma professora e um aluno com autismo na escola comum: uma proposta de intervenção'}

Rosana Carvalho Gomes"

Débora R. P. Nunes"

\section{Resumo}

Os aspectos polêmicos que envolvem o processo de inclusão de educandos com autismo nas salas de aula comuns têm suscitado debates amplos nas últimas décadas. Um dos principais desafios apontados por professores para realizar esse tipo de inclusão são os prejuízos na comunicação, tipicamente evidenciados por alunos com esse diagnóstico. Desse modo, torna-se imperativo o desenvolvimento de programas de intervenção focados no desenvolvimento das habilidades comunicativas desses alunos. Tendo isso em vista, o objetivo do presente estudo foi avaliar os efeitos de um programa de intervenção nas interações comunicativas, no contexto da sala de aula comum, entre um aluno não falante de 10 anos, com diagnóstico de autismo, e sua professora. Os dados foram coletados em uma escola de Ensino Fundamental, localizada na cidade de Natal (RN). No programa de intervenção, a professora foi capacitada a empregar estratégias do ensino naturalístico e recursos da comunicação alternativa ampliada para aumentar a frequência de interações com o aluno durante três rotinas da sala de aula. Com base em um delineamento de pesquisa quase experimental do tipo A-B (linha de base e tratamento) foram identificadas mudanças qualitativas e quantitativas nas interações professoraaluno, logo após a implementação do programa de intervenção. Limitações do estudo são apresentadas e discutidas a partir dos dados observacionais e registros das interações entre a díade.

\section{Palavras-chave}

Educação inclusiva - Autismo - Comunicação alternativa e ampliada.

I- Dissertação de Mestrado financiada pela CAPES.

II- Universidade Federal do Rio Grande do Norte, Natal, RN, Brasil.

Contatos: deboranunes@ufrnet.br;

rosanagomescarvalho@hotmail.com 


\title{
Communicative interactions between a teacher and a student with autism in regular schools: an intervention proposal'
}

\author{
Rosana Carvalho Gomes" \\ Débora R. P. Nunes"
}

\begin{abstract}
The controversial aspects involving the process of inclusion of students with autism in public school classrooms have sparked extensive debate in recent decades. One of the main challenges faced by teachers to perform this type of inclusion are impairments in communication, typically evidenced by students with this diagnosis. Thus, it becomes imperative to develop intervention programs focused on the development of the communicative skills of these students. Keeping this in view, the aim of this study was to evaluate the effects of a program of intervention on the communicative interactions, in the context of common classrooms, between a non-speaking student aged 10 years, diagnosed with autism, and his teacher. Data were collected in a primary education school located in Natal city, Rio Grande do Norte state. In the intervention program, the teacher was trained to employ naturalistic teaching strategies and resources of extended alternative communication to increase the frequency of interactions with the student during three routines of the classroom. Based on a quasi-experimental research design of $A B$ type (baseline and treatment), we identified qualitative and quantitative changes in teacher-student interactions shortly after the implementation of the intervention program. Limitations of the study are presented and discussed on the basis of observational data and records of the interactions between the dyad.
\end{abstract}

\section{Keywords}

Inclusive education - Autism - Extended and alternative communication. 


\section{Introdução}

0 autismo é um transtorno do desenvolvimento neurobiológico, definido por critérios essencialmente clínicos. Passível de ser detectado antes dos 36 meses de vida, o autismo é o mais prevalente e conhecido dentre os Transtornos Globais do Desenvolvimento (TGD), acometendo homens em proporção quatro vezes superior às mulheres. Para que se tenha uma dimensão do contingente populacional de que estamos tratando, ressaltamos que pesquisas epidemiológicas internacionais indicam que os TGD afetam um em cada 160 indivíduos (ELSABBAGH, 2012). No Brasil, os valores são ainda maiores: um estudo conduzido por Paula et al. (2011) sugere que o autismo e suas variações afetam um em cada 350 brasileiros.

No que se segue, passamos a descrever algumas das características típicas de pessoas diagnosticadas com autismo, consideradas por nós como relevantes para o presente estudo. Quanto ao comportamento, à interação social e à comunicação de pessoas diagnosticadas como autistas, percebem-se prejuízos qualitativos e quantitativos bastante marcados (APA, 2002). Nos casos de comportamentos atípicos, por exemplo, pode haver adesão aparentemente inflexível a rotinas desadaptativas, rituais não funcionais, padrões restritos de interesses, além de maneirismos motores estereotipados e repetitivos.

Os prejuízos qualitativos nas interações sociais são evidentes nos comportamentos não verbais, tais como dificuldades em manter o contato visual ou a presença de expressões faciais e posturas corporais atípicas durante interação interpessoal. Cabe, ainda, ressaltar aspectos como o fracasso em desenvolver relacionamento com pares, a falta de reciprocidade emocional e a ausência de tentativas em compartilhar prazer, interesses ou realizações com o outro (APA, 2002).

As alterações da linguagem podem variar de acordo com o grau de severidade do quadro clínico. Para que se tenha uma ideia, aproximadamente 30\% dos autistas são desprovidos da linguagem verbal (KLIN, 2006). Outros, apesar de desenvolverem a linguagem, não apresentam intenção comunicativa ou exibem atipicidades, como ecolalia, inversão pronominal e dificuldades na prosódia (MACEDO; ORSATI, 2011). Adicionalmente, o sistema de comunicação gestual, tanto em indivíduos vocais quanto não vocais, pode ser deficitário (APA, 2002). Além disso, o cometimento na compreensão da linguagem falada é outra característica comum dessa população (MACEDO; ORSATI, 2011; HALL, 2012).

A tríade sintomatológica que caracteriza o perfil da pessoa com autismo não pode ser ignorada no contexto da escola. As especificidades da síndrome podem interferir no aprendizado e na inclusão social desses indivíduos em ambientes educacionais (HALL, 2012; NUNES, 2012). A proximidade física com os colegas, a dificuldade em apreender regras sociais, a falta de compreensão de instruções verbais ou a incapacidade em utilizar a linguagem falada podem representar desafios para essa população.

Vale ressaltar, ainda, que estudos nacionais e internacionais revelam que os professores se sentem despreparados para lidar com a sintomatologia autista no contexto da sala de aula comum, conforme já estudado em diversas ocasiões (MCGREGOR; CAMPBELL, 2001; ROBERTSON; CHAMBERLAIN; KASARI, 2003; ALVES, 2005; MARTINS, 2007; SERRA, 2008). Ao serem interrogados, esses docentes indicam que um dos principais desafios é educar alunos que apresentam limitada competência comunicativa (MCGREGOR; CAMPBELL, 2001).

Os prejuízos comunicativos tipicamente observados nessa população podem ser minimizados pelo uso da Comunicação Alternativa e Ampliada (CAA) (NUNES, 2008; WENDT, 2009; MACED0; ORSATI, 2011). A comunicação alternativa é aquela em que os recursos substituem a fala, e a ampliada é aquela em que esses recursos suplementam a fala.

Estudos sobre CAA no Brasil têm crescido nas últimas décadas (CUNHA, 1997; ARAUJO; 
NUNES, 2003; DELIBERATO, 2009; SCHIRMER; NUNES et al., 2009; PAULA; ENUMO, 2007; WALTER; ALMEIDA, 2010). Trata-se de uma área da prática clínica e educacional que objetiva compensar, temporária ou permanentemente, os prejuízos na comunicação expressiva e receptiva. Ela envolve o uso de gestos manuais, expressões faciais e corporais, símbolos gráficos (fotografias, gravuras, desenhos, linguagem alfabética, objetos reais e miniaturas), voz digitalizada ou sintetizada, dentre outros meios que podem ser usados para efetuar a comunicação face a face de pessoas que apresentam limitações no uso e/ou na compreensão da linguagem oral.

A metodologia de intervenção utilizada para capacitar populações com prejuízos na linguagem a utilizar os recursos da CAA é o Ensino Naturalístico (EN), o qual se tem destacado em muitas das pesquisas realizadas na área (LAMONICA, 1993; NUNES, 2000; PAULA; NUNES, 2003; ARAUJO; NUNES, 2003; NUNES et al., 2009). O EN é um modelo geral de intervenção em linguagem, que inclui diversos programas de tratamento (CUNHA, 1997). De acordo com Nunes (1992), os seguintes elementos são considerados comuns a esses programas: a) o uso de reforçadores indicados pelo aprendiz; b) o interesse da criança, considerado como fio condutor no processo de aprendizagem; c) as contingências do meio natural utilizadas para o aumento na frequência de emissões de respostas desejadas; d) a ênfase dada à competência comunicativa do educando em vez da linguagem per se; e e) o ensino realizado durante atividades cotidianas em contextos e ambientes naturais.

Dentre as estratégias de ensino derivadas da abordagem naturalística, destacam-se: o arranjo ambiental, o modelo dirigido à criança, o mando e a espera. Esses procedimentos, que serão posteriormente defınidos no presente artigo, permitem à criança aumentar a frequência de interação com pessoas e objetos do seu meio (CUNHA, 1997).
Com relação à eficácia desse tipo de abordagem, ressaltamos que, em uma avaliação de programas de intervenção dirigidos para populações com autismo, o uso das Estratégias Naturalísticas de Ensino (ENE) foi categorizado como uma prática cientificamente válida ${ }^{1}$ (NATIONAL AUTISM CENTER, 2013). No contexto educacional, no entanto, o número de estudos que avaliam a eficácia das ENE no ensino da CAA para populações com autismo é limitado (NUNES et al., 2009).

A pesquisa realizada por Nunes et al. (2009) investigou o trabalho de uma professora que recebeu capacitação para utilizar as ENE para ensinar uma menina autista, de 6 anos, a usar os recursos da CAA em um ambiente de sala de aula especial. Os resultados do estudo evidenciaram que a professora, após o programa de treinamento, passou a se comunicar em vários contextos de interação com a criança. Houve generalizações das práticas aprendidas para outro contexto e aumento na frequência de turnos comunicativos da criança.

Tendo em vista a relevância desse tipo de investigação, o presente artigo tem como propósito a ampliação dos estudos nesse campo, focando o uso dos recursos da CAA por aluno com autismo, no contexto da escola comum. Assim, visamos a avaliar os efeitos do emprego de um programa de capacitação do professor para a utilização dos recursos da CAA com um aluno com autismo, por meio de ENE.

\section{Metodologia da pesquisa}

0 presente estudo foi conduzido com Luan, um aluno com diagnóstico de autismo, e Sônia, sua professora. Na ocasião em que realizamos a pesquisa, o menino havia completado 10 anos e estava matriculado no $3^{\circ}$ ano de uma escola comum do Ensino Fundamental. Aos 3 anos, recebera diagnóstico de autismo, por um neuropediatra. Adicionalmente, por meio do

1- Práticas cientificamente válidas são descritas como métodos e técnicas que tenham produzido resultados positivos quando testados experimentalmente (SIMPSON, 2005). 
instrumento Childhood Autism Rating Scale CARS $^{2}$ (PEREIRA et al., 2008), aplicado pelas autoras no início da pesquisa, obtiveram como resultado a constatação de que o grau de autismo de Luan foi considerado severo (52 pontos).

No que se refere ao comportamento, suas verbalizações eram limitadas e desprovidas de intenção comunicativa. A ausência de fala funcional não era compensada pelo uso de gestos ou outras formas não verbais de comunicação. 0 aluno demonstrava, ainda, dificuldade em interagir com seus pares, limitada compreensão da fala e exibição de estereotipias motoras e inflexibilidade comportamental.

Sônia, 41 anos, trabalhava há 14 como professora. Sua formação profissional era de nível médio, no curso de magistério. Embora tivesse experiência como docente em outros estabelecimentos de ensino, não havia trabalhado com crianças com necessidades educacionais especiais, até o momento da pesquisa.

0 estudo foi conduzido em uma sala de aula comum de $3^{\circ}$ ano de uma escola da rede privada de ensino. A instituição, localizada em um bairro de classe média da cidade de Natal (RN), atendia aproximadamente a 120 alunos da Educação Infantil ao Ensino Fundamental.

Foram utilizados alimentos, jogos, atividades pedagógicas e pictogramas contendo fotografias ou símbolos $\mathrm{PCS}^{3}$ dos objetos ou atividades realizadas durante as rotinas escolares. Uma câmera filmadora portátil, uma câmera fotográfica digital e um laptop foram os equipamentos usados.

Para registrar as interações entre professora e aluno, optou-se pelo uso de dois roteiros de entrevista individual e um diário de campo, no qual foram registradas as impressões e anotações da pesquisadora (1 1 autora).

2- CARS - entrevista estruturada, traduzida e validada no Brasil por Pereira e colaboradores (2008), que avalia o comportamento em 14 habilidades tipicamente afetadas pelo autismo. A pontuação varia de 15 a 60, sendo 30 o ponto de corte para o autismo (PEREIRA et al., 2008). A escala auxilia no diagnóstico diferencial e na classificação do grau de severidade da síndrome, como leve, moderada ou severa. A aplicação pode ser feita por profissionais de qualquer área com experiência em autismo. 3- Símbolo PCS - Picture Communication Symbols.
0 presente estudo caracteriza-se como uma pesquisa quase experimental, com um delineamento do tipo A-B (KENNEDY, 2005). As respostas comunicativas da díade professoraaluno constituíram as variáveis investigadas. Essas variáveis foram, inicialmente, categorizadas em tipos de turno, conforme indicado no Quadro 1 abaixo:

Quadro 1 - Tipos de turnos

\begin{tabular}{c:c} 
Turno & \multicolumn{1}{c}{ Definição } \\
\hline \multirow{3}{*}{ Resposta } & $\begin{array}{c}\text { Enunciados verbais/vocais, gestuais (gestos, língua de } \\
\text { sinais e expressões faciais) ou pictográficos emitidos } \\
\text { pelo aluno/professora após pergunta/solicitação do } \\
\text { parceiro. }\end{array}$ \\
\hline \multirow{2}{*}{ Iniciativa } & Enunciados verbais/vocais, gestuais (gestos, língua de \\
& sinais e expressões faciais) ou pictográficos emitidos \\
& pelo aluno/professora sem ocorrência de solicitação \\
de resposta do parceiro.
\end{tabular}

Fonte: Elaboração das autoras do artigo.

Os turnos (iniciativa e resposta) foram, posteriormente, categorizados em cinco modalidades, conforme indicado no Quadro 2, abaixo:

Quadro 2 - Modalidade de turnos

\begin{tabular}{|c|c|}
\hline Modalidade & Definição \\
\hline Gestual & $\begin{array}{l}\text { Olhar, expressão facial, contato corporal e ação } \\
\text { gestual (convencional; simbólica e de contenção) } \\
\text { emitidos pelo aluno ou professora durante um } \\
\text { turno (iniciativa ou resposta). }\end{array}$ \\
\hline Verbal/vocal & $\begin{array}{l}\text { Verbalizações, sons guturais, gemidos, } \\
\text { murmúrios, balbucios ou vocábulos não } \\
\text { inteligíveis emitidos pelo aluno ou professora } \\
\text { durante um turno (iniciativa ou resposta). }\end{array}$ \\
\hline Pictográfica & $\begin{array}{l}\text { Uso de pictograma (fichas com fotos da rotina e } \\
\text { objetos do aluno dispostas na mesa, ou em uma } \\
\text { pasta de comunicação) pelo aluno ou professora } \\
\text { durante um turno (iniciativa ou resposta). }\end{array}$ \\
\hline $\begin{array}{c}\text { Gestual e } \\
\text { pictográfico }\end{array}$ & $\begin{array}{l}\text { Uso simultâneo de duas modalidades: gráfico } \\
\text { (pictogramas) e gestual (gestos manuais/ } \\
\text { corporais e expressões faciais) pelo aluno ou } \\
\text { professora durante um turno (iniciativa ou } \\
\text { resposta). }\end{array}$ \\
\hline $\begin{array}{l}\text { Verbal/vocal e } \\
\text { pictográfico }\end{array}$ & $\begin{array}{l}\text { Uso simultâneo de duas modalidades: verbal } \\
\text { (fala inteligível)/vocal (vocábulos não inteligíveis) } \\
\text { e gráfico (pictogramas) pelo aluno ou professora } \\
\text { durante um turno (iniciativa ou resposta). }\end{array}$ \\
\hline
\end{tabular}

Fonte: Elaboração das autoras do artigo. 
Como se trata de um estudo no qual as autoras participaram ativamente das interações entre Luan e Sônia, cabe apontar para o fato de que a primeira autora, com formação em pedagogia, atuou como agente de capacitação. Ela exercia, há dez anos, a função de pedagoga, tendo trabalhado durante cinco anos com crianças com deficiência em escola comum no estado do Piauí. No presente manuscrito, essa será identificada como pesquisadora.

0 projeto foi inicialmente submetido ao Comitê de Ética em Pesquisa da Universidade Federal do Rio Grande do Norte (Parecer $\mathrm{n}^{-}$ 038/2010; CAAE no 0212.0 051.000-09). A formalização do consentimento se deu por meio de um Termo de Consentimento Livre e Esclarecido (TCLE), assinado pela mãe do aluno e pela professora.

Após a aprovação do projeto pelo Comitê de Ética e a assinatura do TCLE, o estudo foi operacionalizado em seis etapas distintas: entrevistas/observações, treinamento dos assistentes de pesquisa, identificação das rotinas-alvo, linha de base, capacitação e intervenção. Cada uma delas foi descrita abaixo:

\section{Etapa 1: entrevistas/observações.}

A pesquisadora realizou uma entrevista com a mãe e outra com a professora de Luan, na casa e na escola do aluno, respectivamente. Os encontros, com duração aproximada de 60 minutos, foram estruturados considerandose um roteiro de entrevista previamente elaborado pelas autoras. Com o propósito de complementar os dados das entrevistas, assim como identificar as habilidades comunicativas do aluno no contexto escolar, a pesquisadora realizou quatro sessões de observação de Luan, com duração média de 60 minutos, no ambiente escolar. Os dados foram devidamente registrados em um diário de campo.

\section{Etapa 2: treinamento dos assistentes} de pesquisa.

Duas alunas graduandas do curso de pedagogia da Universidade Federal do Rio Grande do Norte foram treinadas no sentido de categorizarem as variáveis previamente definidas. Ambas foram bolsistas, durante três anos, em um projeto de pesquisa envolvendo o uso da comunicação alternativa para alunos com autismo. A capacitação dessas duas bolsistas foi implementada pelas autoras e envolveu procedimentos como discussões, análise de vídeos e leituras. Após a familiarização com os procedimentos empregados, as assistentes classificaram as sessões de linha de base e intervenção. Ao término das videogravações, realizadas pela pesquisadora, as sessões eram então entregues às alunas. Cada assistente ficou responsável pela categorização de 50\% das sessões. Com o propósito de verificar o grau de fidedignidade das categorias de respostas analisadas no presente estudo, a pesquisadora, atuando como segunda avaliadora, randomicamente avaliou 50\% do total das sessões analisadas pelas duas assistentes. Vale ressaltar que as assistentes de pesquisa atuaram como primeiras avaliadoras. 0 cálculo de concordância foi obtido por meio do índice de concordância descrito por Fagundes (1985). Esse índice variou entre 73 e 100\%, indicando boa fidedignidade.

\section{Etapa 3: Identificação das rotinas alvo.}

A partir dos registros de observações e entrevistas foram selecionadas, junto com a professora, três rotinas durante as quais ocorreriam as intervenções: no decorrer do lanche, em atividades pedagógicas e na entrada da escola. Essas rotinas foram escolhidas porque aconteciam diariamente e pelo fato de a professora expressar dificuldade em se comunicar com o aluno durante as referidas atividades. No presente artigo, serão 
apresentados os resultados das duas primeiras rotinas: lanche e atividade pedagógica.

\section{Etapa 4: Linha de base.}

Nessa fase, a professora foi instruída a interagir livremente com o aluno nas três rotinas selecionadas. As sessões foram videografadas, e a frequência de turnos e a modalidade de respostas utilizadas pela díade foram mensuradas. Houve também avaliação a respeito do fato de a professora utilizar ou não, de forma espontânea, as ENE. Os critérios foram definidos no Quadro 3, abaixo: ${ }^{4}$

Quadro 3 - Estratégias naturalísticas de ensino utilizadas no estudo

\begin{tabular}{c|c}
\hline Estratégias & \multicolumn{1}{c}{ Definição } \\
\hline \multirow{3}{*}{ Arranjo ambiental } & Consiste na organização do ambiente com \\
& pictogramas acessíveis ao aluno e objetos de \\
& seu interesse dispostos em seu campo visual, \\
& mas fora de seu alcance. \\
& A professora tece comentários, formula \\
& perguntas e faz solicitações utilizando, \\
& simultaneamente, a linguagem oral e o sistema \\
& pictográfico de comunicação. \\
\hline \multirow{3}{*}{ Mando com CAA } & A professora oferece ajuda física com o \\
& objetivo de guiar o aluno para fixar a atenção \\
& no que está fazendo. Esse procedimento é \\
& acompanhado por comentários, perguntas ou \\
& solicitações verbais. \\
\hline \multirow{3}{*}{ Espera } & A professora aguarda, de forma silenciosa, a \\
& iniciativa de interação do aluno. \\
\hline
\end{tabular}

Fonte: Elaboração das autoras do artigo.

A análise dessas estratégias foi realizada da seguinte maneira: a pesquisadora assistia às sessões videografadas, as quais haviam sido codificadas, e transcrevia os episódios em que as ENE eram utilizadas por Sônia.

\section{Etapa 5: capacitação}

Essa etapa teve início quando foi evidenciada, por meio de inspeção visual

4- Essas estratégias foram adaptadas de estudos realizados previamente por Oliveira (2002), Souza (2000), Nunes (2000; 2005) e Danelon (2009). dos gráficos, a estabilidade na frequência de turnos da professora na rotina do lanche. Foram realizados, na escola, três encontros de capacitação com a professora. Nesses episódios, Sônia compartilhou com a pesquisadora seu planejamento bimestral, no qual estavam descritos os conteúdos acadêmicos. Em seguida, foram apresentados segmentos de sessões de linha de base à professora. A partir do material videografado, a professora e a pesquisadora elencaram fatores que pareciam prejudicar a interação da díade, assim como aspectos positivos do comportamento de Luan e da própria docente. A partir dessas discussões, foram descritos os conceitos de Comunicação Alternativa e Ampliada e apresentadas as quatro ENE, previamente definidas neste manuscrito. Com o auxílio da pesquisadora, foram confeccionados pictogramas ${ }^{5}$ a serem empregados durante as três rotinas e reelaboradas as atividades acadêmicas apresentadas no planejamento de Sônia.

\section{Etapa 6: intervenção}

Ao término da capacitação, Sônia foi instruída a utilizar as estratégias aprendidas nas rotinas em que recebeu o treinamento. Ela não recebia instruções da pesquisadora durante esses episódios, mas, nos encontros subsequentes, a pesquisadora fornecia dicas pontuais sobre as interações previamente realizadas. As rotinas foram videografadas, e, posteriormente, analisados: a frequência de turnos, a modalidade de respostas da díade e os tipos de ENE empregados pela professora.

Dois roteiros de entrevista foram elaborados pelas autoras. No instrumento utilizado com a mãe constavam itens sobre o desenvolvimento do aluno, seu histórico social e escolar, assim como suas rotinas em casa. Com a professora, o roteiro incluía perguntas sobre o comportamento de Luan em sala de aula e os tipos de atividades realizadas com o aluno. As entrevistas foram gravadas e transcritas pela pesquisadora.

5- Fotos da rotina de Luan na sala de aula (lavar as mãos, lancheira, biscoito, batata, água). 
As sessões de linha de base e intervenção foram videografadas pela pesquisadora. 0 tempo de duração das interações variava de cinco a dez minutos, aproximadamente. Para fins de análise e controle da variável tempo, apenas os primeiros cinco minutos de interação foram considerados nas avaliações.

A análise dos dados ocorreu em duas etapas. Inicialmente, as variáveis turno e modalidade de respostas foram codificadas pelas assistentes de pesquisa e pela pesquisadora. A frequência dessas variáveis foi disposta em gráficos. Posteriormente, a pesquisadora revisou as sessões codificadas e transcreveu os episódios em que as ENE foram empregadas pela professora.

Tratando-se de uma pesquisa quase experimental (A-B), a análise ocorreu por meio de inspeção visual dos dados plotados graficamente. Dessa forma, as variáveis (turno e modalidade de respostas) foram categorizadas e, posteriormente, suas frequências disponibilizadas em gráficos.

0 critério para finalizar a fase de linha de base e iniciar a capacitação foi a estabilidade observada na frequência de turnos da professora em uma das rotinas selecionadas, conforme exposto anteriormente. Em seguida, as mesmas sessões foram analisadas pela pesquisadora, que transcreveu os episódios em que as ENE foram empregadas nas fases de linha de base e de intervenção. As informações dos gráficos e as transcrições da pesquisadora foram complementadas com os dados das entrevistas e do diário de campo.

\section{Resultados}

0 objetivo geral do presente estudo foi avaliar os efeitos de um programa de intervenção nas interações comunicativas entre um aluno com diagnóstico de autismo e sua professora, no contexto da sala de aula comum. A partir desse objetivo, três questões norteadoras da pesquisa foram elaboradas:

1. Quais os efeitos do programa de capacitação no uso de estratégias de ensino empregadas pela professora?
2. Quais os efeitos do programa de capacitação nos turnos (iniciativas e respostas) da professora e do aluno?

3. Quais os efeitos do programa de capacitação nas modalidades dos turnos da díade?

As respostas foram extraídas dos diários de campo e da análise das sessões videografadas, no decorrer dos cinco meses de estudo. No total, foram realizadas 22 sessões (11 de linha de base e 11 de intervenção), em cada rotina.

Quanto aos efeitos do programa de capacitação no uso das estratégias de ensino empregadas pela professora, destacou-se o fato de que antes da intervenção foram detectadas situações nas quais as ENE poderiam ter sido empregadas no momento do lanche, o que não ocorreu. Esse fato foi particularmente evidenciado na sessão três, linha de base, descrita a seguir:

Neste dia há dois cartões sobre a mesa de Luan, o da água e o da atividade pedagógica. Outros cartões de alimentos (batata e biscoito) e atividades rotineiras (lavar as mãos) estão na mesa da professora, fora do campo visual do aluno. A professora se aproxima de Luan e diz: “Lanchar, vambora!" Ela o conduz pela mão até o banheiro e fornece ajuda física para que ele lave as mãos. Eles voltam para a sala de aula. Luan senta em sua carteira e a professora caminha até a prateleira. Ela pega a lancheira de Luan, abre e leva até ele. Ele olha para a lancheira. Ela pergunta: "Você quer batatinha ou biscoito?". Ele pega o pacote de batatas. Ela toma o pacote das mãos de Luan, abre e devolve a ele. (GOMES, cd 1, 2010)

Na sessão explicitada acima, alguns dos pictogramas que Luan poderia ter utilizado durante a interação estavam fora de seu campo visual. 0 emprego de estratégias como o mando com CAA, a espera e o arranjo ambiental pela professora seria apropriado no contexto descrito. Sendo assim, ela poderia ter 
sinalizado a rotina de lavar as mãos e lanchar utilizando os pictogramas que estavam em sua mesa (mando com CAA). Da mesma forma, poderia ter mostrado ao aluno os pictogramas da batata e do biscoito, incitando-o a indicar o que gostaria de lanchar. Em seguida, em vez de abrir o pacote de batatas para ele, poderia ter utilizado o procedimento de espera para estimular a iniciativa de interação do aluno. 0 saco de batatas poderia ter permanecido com a professora e oferecidas poucas batatas, por vez, a ele. Isso caracterizaria o procedimento de arranjo ambiental, que poderia favorecer o aumento na frequência de iniciativas de interação do aluno.

0 relato da sessão cinco (linha de base) evidencia a carência de uso das ENE durante as rotinas pedagógicas. Nessa sessão, a turma está realizando uma atividade de matemática enquanto Luan senta no fundo da sala manipulando, de forma estereotipada, um pincel. Na mesa de Luan há seis pictogramas, duas cédulas de 2 e 5 reais e duas cópias pequenas das mesmas notas. A proposta da atividade é para que Luan coloque as cópias das cédulas sobre as notas originais.

A professora se aproxima de Luan e retira o pincel de sua mão, dizendo: "Tá bom, você já brincou demais!”. Ela puxa o menino para cima, pelas mãos. Ele resiste, contraindo o corpo para o chão. Ela diz: "Venha!". Ele levanta e senta na carteira. Ela mostra: "Olha Luan, 2 reais! Coloca aqui, ó!”. Ela aponta para a nota original, solicitando que ele coloque a cópia sobre ela. (GOMES, cd 1, 2010)

A falta de responsividade de Luan pode ter sido em função da dificuldade de compreender a fala da professora. Assim, a professora poderia ter utilizado os pictogramas das atividades enquanto dava comandos verbais ao aluno (mando com CAA). Cabe enfatizar que o uso de duas modalidades de expressão (verbal e pictográfica) pode favorecer a compreensão de alguns alunos com diagnóstico de autismo (HEFLIN; ALAIMO, 2007).

Apesar de ter acesso aos pictogramas na interação descrita, Luan não os utilizou como alternativa de expressão. Podemos atribuir esse comportamento à falta de instruções explícitas de como utilizá-los. Isso porque estudos anteriores apontam que a mera exposição da pessoa com autismo aos recursos da CAA pode ser pouco eficaz para o desenvolvimento de novas formas de expressão (NUNES et al., 2009).

Após o programa de capacitação, foram identificados episódios em que as estratégias de ensino foram adequadamente utilizadas. 0 relato da sessão 16 (intervenção) abaixo, indicou o uso apropriado do arranjo ambiental durante a atividade de lanche:

Luan está sentado no chão no canto da sala. Na carteira dele, localizada ao lado da professora, há oito cartões de CAA, incluindo o pictograma da lancheira e do copo. A lancheira e o copo encontram-se na prateleira, no canto da sala, à vista dele, mas fora de seu alcance. (GOMES, cd 2, 2010)

No exemplo acima, observa-se o uso de arranjo ambiental, uma vez que a professora colocou os objetos à vista do aluno, mas longe de seu alcance. Essa organização do ambiente físico pode instigar, conforme evidenciado na literatura, iniciativas de interação social (NUNES, 1992). No caso de Luan, poderia estimulá-lo a utilizar os pictogramas para solicitar sua lancheira, que estava inacessível.

$\mathrm{Na}$ atividade pedagógica da sessão 16, descrita a seguir, o aluno tinha à sua frente várias gravuras de animais separados por quantidade e colocados em sequência de ordem numérica. A proposta da atividade era que Luan colocasse duas fichas ao lado de cada gravura.

A professora aponta para a gravura e diz: "Olhe uma vaquinha Luan! Coloca aqui Luan, o número 1 de uma vaquinha!". Ela permanece em silêncio, observando o 
menino por alguns segundos. Ele pega a figura da vaca. Ela verbaliza: "A vaquinha não Luan, o numeral 1. Vá Luan, uma vaquinha, o número 1!". Luan posiciona a mão sobre o numeral 1 e olha para a professora. Ela aponta para a gravura da vaca e, em seguida, para o numeral. Ela diz: "Agora uma bolinha, pega Luan!". Ele pega a ficha com as bolinhas e põe ao lado da figura da vaca. Ela verbaliza e aponta para as fichas: "Olha Luan, que lindo! Uma vaquinha, o numeral 1 e uma bolinha! Muito bem Luan! [...]”. (GOMES, 2010, cd 2)

No episódio acima descrito, a professora realizou a tarefa com Luan utilizando as gravuras da atividade e a linguagem verbal, de forma simultânea. Sempre que o aluno desviava o olhar ou resistia em pegar os materiais, ela chamava a sua atenção, pegava sua mão e colocava em cima da gravura, reiniciando a ação com comando de voz e indicação das fichas. 0 pareamento de estímulos verbais e visuais empregado por Sônia pode ter favorecido a compreensão do aluno, mantendo-o atento à tarefa.

0 procedimento de espera ocorreu quando a professora pediu para Luan pegar as gravuras e colocar nos lugares apontados por ela. Nesses episódios, era dado um tempo de aproximadamente dez segundos para ele dar a resposta. Quando não havia resposta, a professora repetia a ação, provendo dicas verbais ou ajudando-o fisicamente no prosseguimento da atividade.

Apresentados alguns dos principais procedimentos verificados na interação entre Luan e Sônia, no que se segue apresentam-se os efeitos do programa de capacitação nos turnos da díade nas rotinas investigadas, por meio do gráfico 1, a qual indica a frequência de turnos da díade nas sessões de lanche.

\section{Gráfico 1 - Lanche: frequência de turnos da professora e do aluno}

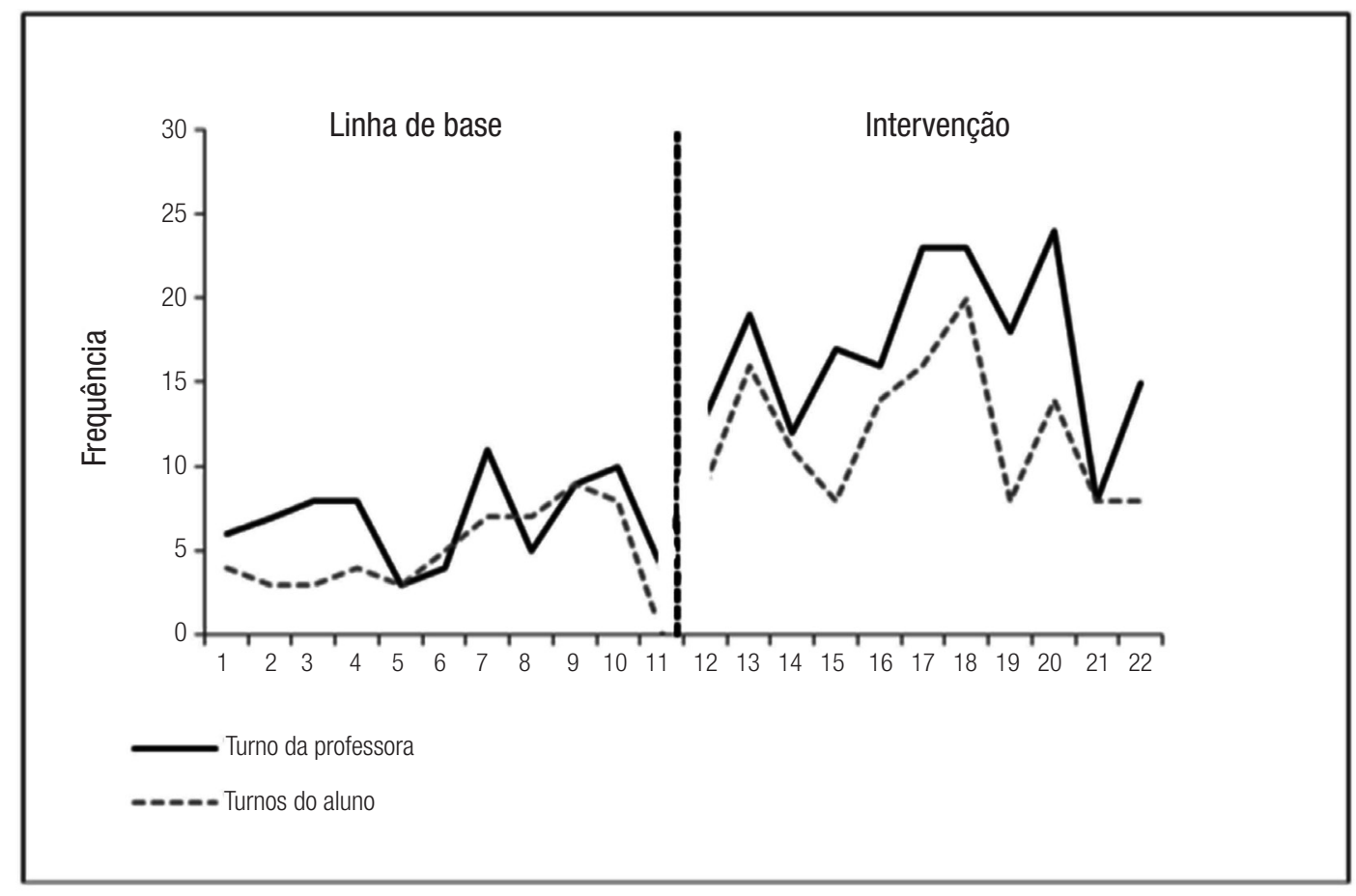

Fonte: dados da pesquisa. 
0 Gráfico 1 sugere relativa estabilidade e baixa frequência de turnos comunicativos da professora e do aluno nas sessões de linha de base. Esse fenômeno pode ser justificado pelo distanciamento físico da díade professora-aluno. No momento do lanche, Sônia tipicamente entregava os alimentos a Luan e retornava à sua mesa. Ele, por sua vez, permanecia em seu assento, até consumir a merenda. A interação de Sônia com Luan limitava-se a comandos verbais, solicitando sua permanência na carteira até finalizar o lanche. Ele, por vezes, vocalizava e dirigia o olhar para a professora, mas, em geral, suas iniciativas de interação não eram percebidas por ela.

0 aumento na frequência de ocorrência de turnos da díade na fase intervenção pode ser observado no gráfico 1. Essa tendência ascendente pode ter sido ocasionada pelas estratégias implementadas pela professora após o programa de capacitação. A proximidade física estabelecida com o aluno, que começou a sentarse ao seu lado, parece ter também favorecido o aumento na frequência das interações.

0 gráfico 2 indica a frequência de turnos da díade nas rotinas da atividade pedagógica.

Gráfico 2 - Atividade pedagógica: frequência de turnos da professora e do aluno

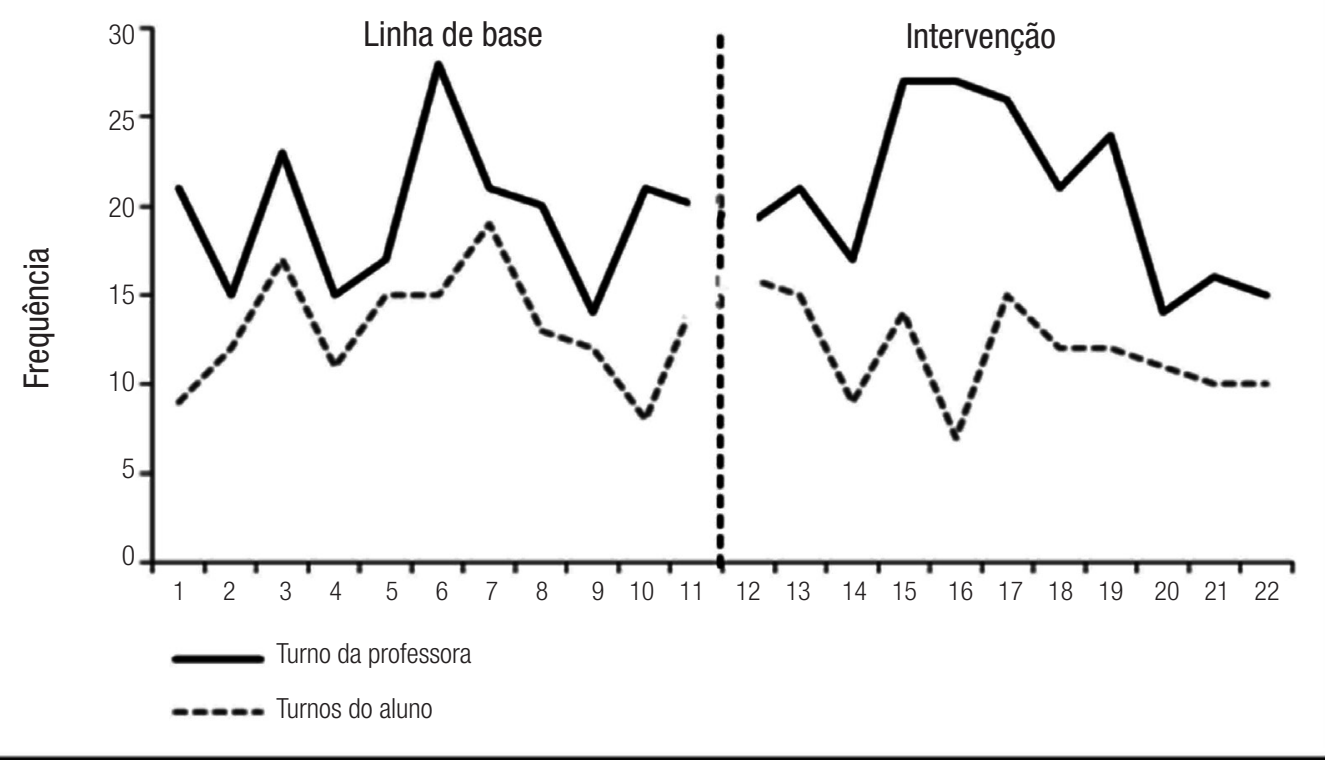

Fonte: dados da pesquisa

A maior frequência de interação da díade ocorreu durante as atividades pedagógicas. Esse padrão de respostas pode ser justificado pelo fato de ser o único momento em que a professora se sentava por mais tempo para interagir, individualmente, com o aluno. Apesar da elevada frequência, a qualidade da interação durante a fase de linha de base nem sempre era positiva.
Luan mostrava-se pouco responsivo às tarefas propostas pela professora antes da intervenção. Essa baixa responsividade se manifestava por comportamentos como: reduzida frequência em dirigir o olhar para a atividade, lassidão das mãos no momento de segurar os lápis, estereotipias motoras e tentativas de levantar-se da carteira. Nessas 
ocasiões, a professora ficava em pé, na frente dele, fazendo contenção física e empregando elogios para mantê-lo na tarefa.

0 comportamento de desinteresse de Luan pode ser atribuído à falta de compreensão ou motivação para realizar as atividades. De fato, dados observacionais revelaram que, muitas vezes, as tarefas propostas antes da intervenção pareciam inapropriadas para ele. Foram identificados poucos momentos em que Sônia individualizou a atividade pedagógica, considerando as necessidades educacionais específicas de Luan. Conforme aludem Oliveira e Machado (2007), a falta de adaptação curricular pode determinar a menor participação acadêmica do educando com necessidades educacionais especiais na sala de aula comum. Nesse contexto, as estereotipias motoras e outras condutas desadaptativas observadas durante essas atividades possivelmente refletem $o$ não envolvimento de Luan com as tarefas.

De maneira geral, após a implementação do programa de capacitação, as atividades propostas passaram a ser mais bem adaptadas e realizadas, em grande parte, com o apoio de pictogramas. Conforme sugerido na literatura, o uso de recursos visuais pode facilitar a compreensão de educandos com autismo
(WENDT, 2009). Esse parece ter sido o caso de Luan. Como possível consequência da introdução dos recursos de CAA, foi observada melhora qualitativa nas interações estabelecidas pela díade. Sônia passou a interagir com Luan não apenas para redirecioná-lo para a tarefa, mas também para tecer comentário e fazer solicitações durante as atividades.

0 aumento na frequência de turnos da professora foi acompanhado pelo aumento na frequência de turnos do aluno, tanto na rotina do lanche quanto durante as atividades pedagógicas. Na medida em que a professora diminuía a frequência de turnos, o aluno comportava-se de forma semelhante. Conforme argumenta Carvalho (1986, 2003, p. 90), "o comportamento do aluno influencia o comportamento do professor e vice-versa".

Para tratar a respeito dos efeitos do programa de capacitação nas modalidades de respostas empregadas pela díade, apresentamos a tabela 1. Ela indica o somatório da frequência dos turnos gestuais, verbais/vocais, pictográficos, verbais/vocais/gestuais e verbais/ vocais/pictográficos empregados pela díade durante todas as sessões de linha de base e intervenção na hora do lanche.

Tabela 1 - Somatório das frequências de modalidades de turnos empregados pela díade nas rotinas de lanche

\begin{tabular}{|c|c|c|c|c|}
\hline & \multicolumn{2}{|c|}{ Professora } & \multicolumn{2}{|c|}{ Aluno } \\
\hline & Linha de base & Intervenção & Linha de base & Intervenção \\
\hline Gestual & 10 & 13 & 23 & 57 \\
\hline Verbal/vocal & 25 & 69 & 16 & 32 \\
\hline Pictográfico & 6 & 2 & 12 & 29 \\
\hline Verbal/vocal/ Gestual & 20 & 33 & 1 & 5 \\
\hline Verbal/vocal/Pictográfico & 12 & 66 & 0 & 9 \\
\hline Total & 73 & 183 & 52 & 132 \\
\hline
\end{tabular}

Fonte: Dados da pesquisa.

De modo geral, esses dados refletem um aumento na frequência de turnos empregados pela díade, nas diferentes modalidades, na rotina de lanche, após o programa de capacitação. A única exceção é uma ligeira queda na frequência de turnos pictográficos pela professora.

Os gráficos 3 e 4 indicam a porcentagem de cada modalidade de turno empregada nas sessões de linha de base e intervenção na hora do lanche. 
Gráfico 3 - Porcentagem das modalidades de turnos empregados pela professora na hora do lanche

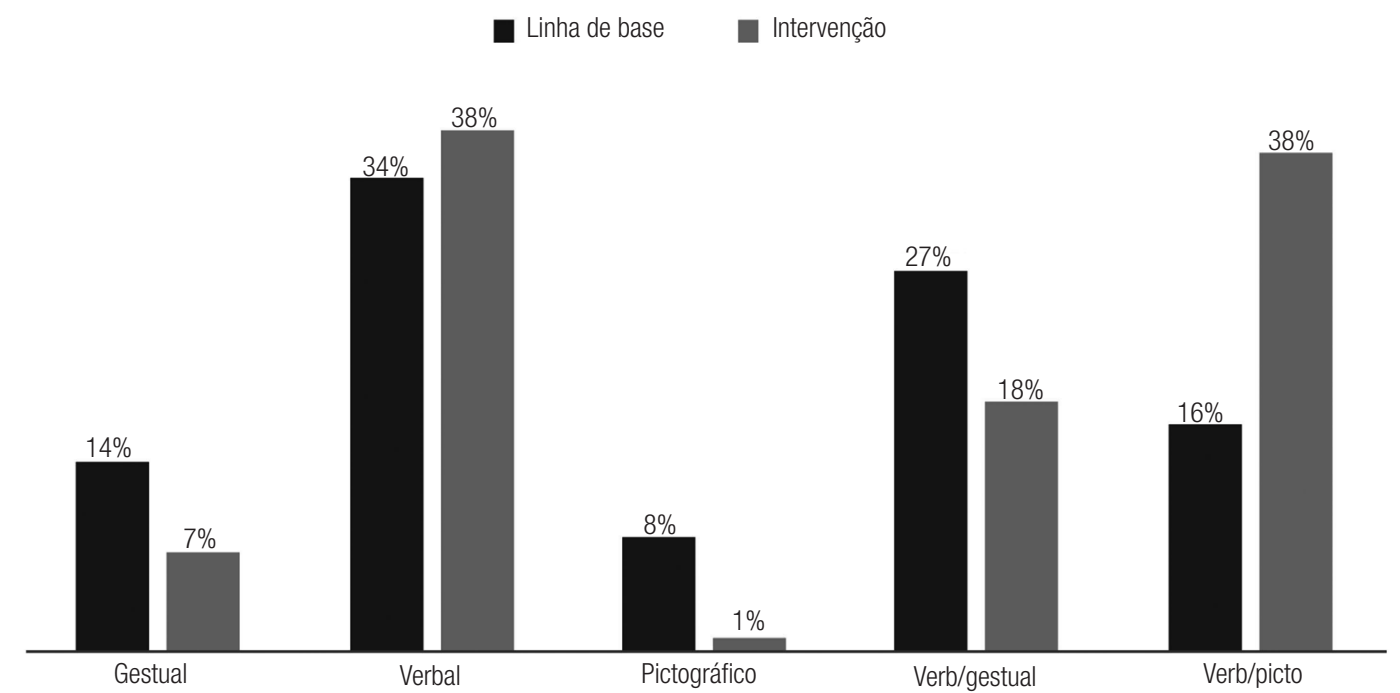

Fonte: Dados da pesquisa.

Gráfico 4 - Porcentagem das modalidades de turnos empregados pelo aluno na hora do lanche

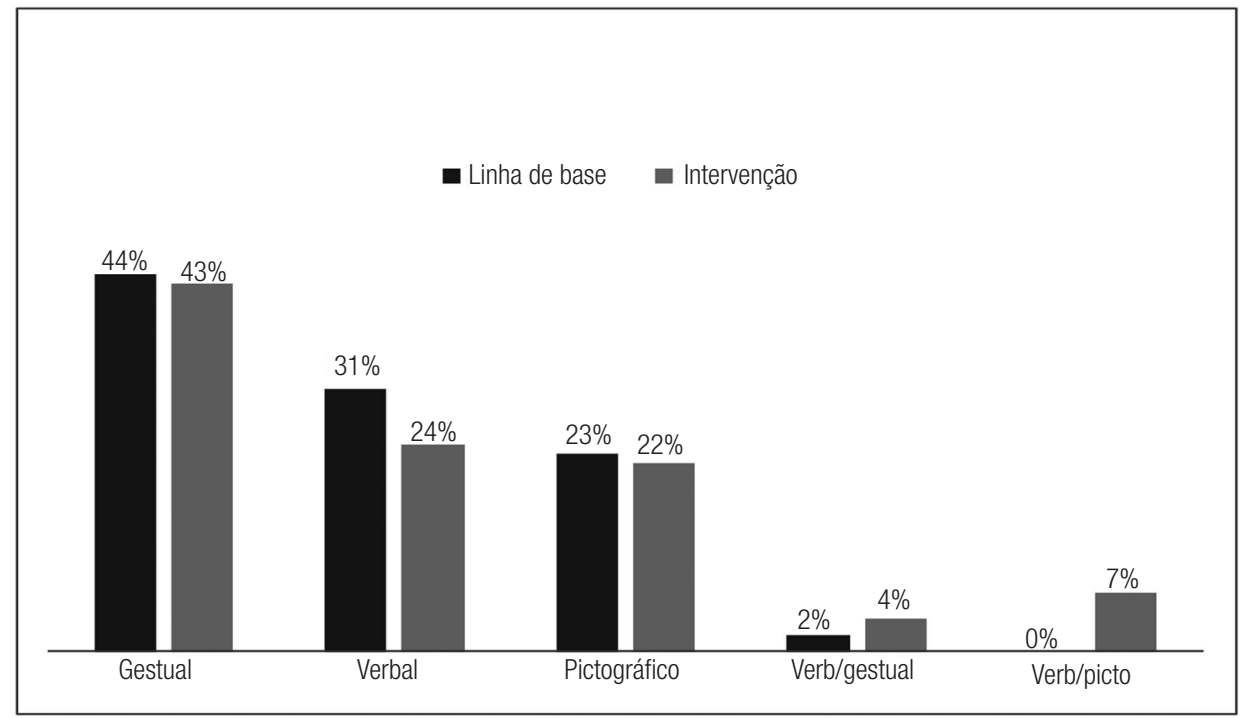

Fonte: Dados da pesquisa.

0 gráfico 3 revela que a professora, tipicamente, interagia com Luan por meio de verbalizações acompanhadas ou não por gestos, antes da intervenção. Após a capacitação, foi observado aumento expressivo no emprego dos pictogramas associados à verbalização/ vocalizações e diminuição de turnos gestuais.
Esses dados sugerem que Sônia substituiu os gestos pelo uso dos cartões de comunicação, como ilustra o trecho a seguir:

Luan está no canto da sala com um jogo de memória do "Menino Maluquinho" nas maõs. A professora pega o cartão de 
“lavar as mãos" que está sobre a sua mesa. Ela caminha até o menino e aponta para o cartão, enquanto diz: "Vamos lavar as mãos para depois lanchar, vamos Luan?" (GOMES, cd 2, 2010)

Em relação a Luan, é observada a preferência pelas modalidades gestuais e verbais/vocais, antes da intervenção, conforme revela o gráfico 4. Essa tendência é mantida após a capacitação. Vale ressaltar, no entanto, o aumento de turnos verbais/vocais associados ao uso de pictogramas. A partir desses dados é possível conjecturar que Luan passou a explorar outras modalidades de expressão, como o uso de pictogramas, após o programa de intervenção.

A Tabela 2, abaixo, indica o somatório da frequência dos turnos gestuais, verbais, pictográficos, verbais/gestuais e verbais/ pictográficos empregados pela díade durante todas as sessões de linha de base e intervenção na rotina de atividades pedagógicas.

Tabela 2 - Somatório das frequências de modalidades de turnos empregados pela díade nas rotinas de atividades pedagógicas

\begin{tabular}{|c|c|c|c|c|}
\hline & \multicolumn{2}{|c|}{ Professora } & \multicolumn{2}{|c|}{ Aluno } \\
\hline & Linha de base & Intervenção & Linha de base & Intervenção \\
\hline Gestual & 12 & 10 & 73 & 56 \\
\hline Verbal/vocal & 37 & 38 & 16 & 22 \\
\hline Pictográfico & 9 & 0 & 39 & 40 \\
\hline Verbal/vocal / Gestual & 65 & 69 & 16 & 12 \\
\hline Verbal/vocal /Pictográfico & 92 & 110 & 2 & 1 \\
\hline Total & 215 & 227 & 146 & 131 \\
\hline
\end{tabular}

Fonte: dados da pesquisa.

Assim como na rotina de lanche, a professora evidenciou aumento da frequência de turnos após a intervenção. Foi observada, também, uma diminuição no uso de pictogramas de forma isolada e um aumento na modalidade verbal, associada ou não ao uso dos cartões de comunicação por Sônia. Luan, por sua vez, diminuiu a frequência de turnos, após a implementação do programa. De forma específica, vocalizou mais e empregou menos gestos associados ou não a vocalizações. As outras modalidades de expressão não apresentaram alterações expressivas.

Os gráficos 5 e 6 , que se seguem, indicam a porcentagem de cada modalidade de turno empregada nas sessões de linha de base e intervenção nas atividades pedagógicas.

De forma geral, o programa de intervenção parece ter produzido poucas alterações no que concerne às modalidades de comunicação empregadas pela professora durante as rotinas pedagógicas. Sônia priorizou, antes e após a intervenção, o uso de verbalizações associadas a pictogramas e gestos. Em seguida, focalizou expressões verbais isoladas. Por fim, ela utilizou, de forma mais tímida, gestos e pictogramas para se comunicar com Luan antes e depois da intervenção. Vale ressaltar, no entanto, que, assim como na rotina de lanche, houve aumento no emprego das verbalizações associadas ao uso de pictogramas e diminuição na porcentagem geral de gestos.

Após o programa de intervenção, Luan apresentou leve crescimento no uso de formas pictográficas e verbais/vocais de expressão. Foram detectados a diminuição no emprego de gestos e gestos associados a verbalizações/vocalizações. A utilização de formas verbais de expressão associada ao uso da comunicação alternativa manteve-se estável nas duas fases do estudo. 
Gráfico 5 - Porcentagem das modalidades de turnos empregados pela professora na atividade pedagógica

Linha de base — Intervenção

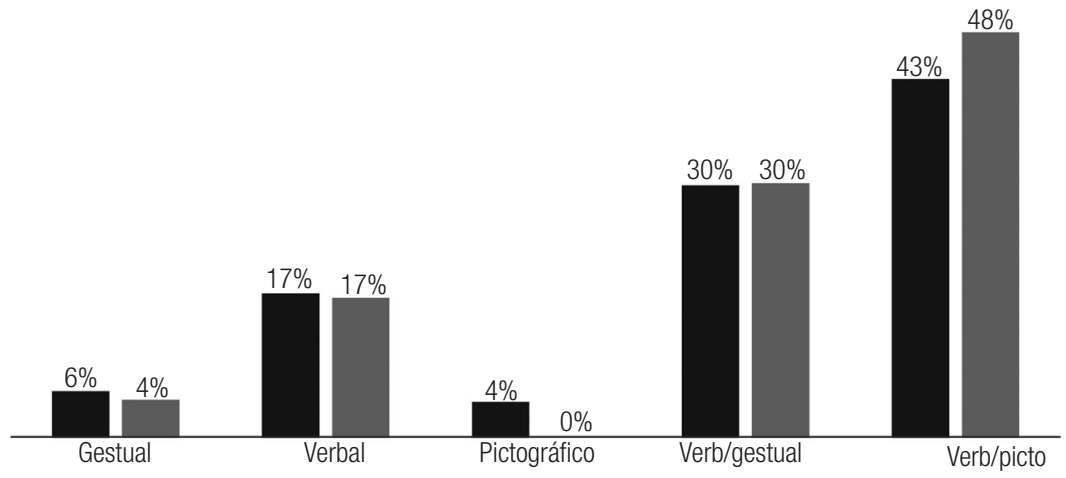

Fonte: dados da pesquisa.

Gráfico 6 - Porcentagem das modalidades de turnos empregados pelo aluno na atividade pedagógica

Linha de base Intervenção

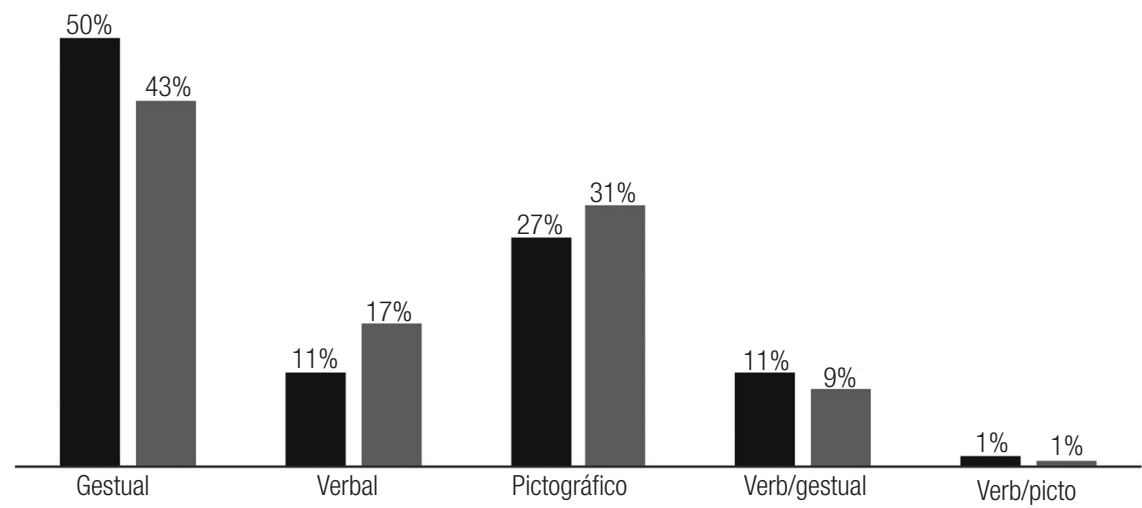

Fonte: dados da pesquisa.

\section{Discussão}

0 objetivo do presente estudo foi avaliar os efeitos de um programa de intervenção psicopedagógica nas interações comunicativas entre um aluno não falante, na faixa etária de 10 anos, com diagnóstico de autismo, e sua professora, no contexto da sala de aula comum. De forma específica, a investigação buscou identificar os efeitos do programa: a) no uso das ENE empregadas pela professora; b) nos turnos da díade; e c) nas modalidades de respostas da díade. 0 estudo foi delineado como uma pesquisa quase experimental do tipo A-B, tendo como cenário duas rotinas escolares: a hora do lanche e as atividades acadêmicas.

Os resultados indicaram momentos de baixa frequência de interação social entre 
Sônia e Luan no início da pesquisa. 0 uso de verbalizações como modalidade de expressão era predominante no repertório da professora, e o uso de gestos, no repertório de Luan. Como forma de aumentar a frequência de interações na díade, objeto do presente estudo, um programa de capacitação foi proposto à professora. Esta, ao rever sua prática nas sessões videografadas, expôs suas angústias e sinalizou as dificuldades de interagir com o aluno. Em seguida, em colaboração com a pesquisadora, identificou estratégias que poderiam favorecer essa interação. Nesse contexto, a pesquisadora apresentou as ENE e os recursos da CAA como forma de incitar a comunicação. 0 caráter individualizado do programa parece ter sido de fundamental importância para a adesão da professora à proposta de intervenção.

Após a capacitação, Sônia aumentou a frequência de turnos comunicativos e o uso de pictogramas associados a enunciados verbais, e demonstrou adequado emprego das ENE nas duas rotinas investigadas. A ampliação na frequência de turnos do aluno foi observada nas rotinas de lanche, mas não durante as atividades pedagógicas. 0 uso dos recursos de CAA por Luan ganhou notoriedade nas sessões de lanche, após o programa de capacitação. A utilização de gestos, no entanto, permaneceu sendo a principal forma de expressão de Luan, nas duas rotinas investigadas.

\section{Consideraçōes finais}

A literatura científica revela resultados promissores sobre o uso dos recursos da CAA e de Estratégias Naturalísticas de Ensino no desenvolvimento das habilidades de comunicação de indivíduos desprovidos de fala articulada, como os autistas. A transposição dessas práticas da teoria para a sala de aula pode ser viabilizada pela participação ativa do professor, como agente de intervenção, em programas instrucionais como o apresentado no presente manuscrito.

Limitações metodológicas são evidenciadas no presente estudo. Como em qualquer pacote de intervenções, em que múltiplas estratégias são ensinadas, é difícil estabelecer o nível apropriado de cada variável independente para otimizar respostas (TANNOCK; GIROLAMETTO, 1992). Ou seja, caso Sônia tivesse empregado as ENE ou os recursos da CAA com uma frequência distinta, haveria diferença na frequência de turnos e modalidades de expressões de Luan? Qual estratégia foi mais efetiva? Outros estudos podem enfocar a avaliação de cada estratégia, de forma isolada.

Foram observados perfis distintos de comunicação da professora nas duas rotinas investigadas, antes e após a intervenção. Enquanto Sônia priorizou a modalidade verbal nas rotinas do lanche, a utilização de verbalizações associadas ao uso dos pictogramas foi mais frequente durante as atividades pedagógicas, nas duas fases do estudo. Esse fenômeno pode evidenciar uma diferença estrutural nas rotinas investigadas. Em outras palavras, a atividade em si pode favorecer o uso de diferentes formas de expressão. Nesse sentido, é preciso que futuras pesquisas atentem para rotinas estruturalmente similares, quando delineamentos experimentais do tipo linha de base são empregados. 


\section{Referências}

ALVES, Márcia Doralina. As representações sociais de professores acerca da inclusão de alunos com distúrbios globais do desenvolvimento. 2005. 103 f. Dissertação (Mestrado em Educação) - Universidade Federal de Santa Maria, Santa Maria, 2005.

AMERICAN PSYCHIATRIC ASSOCIATION-APA. Manual diagnostic e estatístico de transtornos mentais - DSM-IV-TR. Porto Alegre: Artemed, 2002.

ARAÚJO, Maria Isabel; NUNES, Leila Regina de Paula. Facilitando e ampliando a comunicação e os resíduos da fala através de sistema computadorizado de comunicação alternativa. In: NUNES, Leila Regina (Org.). Favorecendo o desenvolvimento da comunicação em crianças e jovens com necessidades educacionais especiais. Rio de Janeiro: Dunya, 2003. p. 111-123.

CARVALHO, Ana Maria. Pimenta. Estudo descritivo da interação professor-aluno: uma abordagem individualizada. 1986. Dissertação (Mestrado em Educação Especial) - Universidade Federal de São Carlos, São Carlos, 1986.

CUNHA, Ana Cristina Barros da. Promovendo aquisição de linguagem funcional em criança deficiente visual: 0 efeito de um treinamento de mãe em procedimentos de ensino naturalístico. Temas Psicol. [online], v. 5, n. 2, p. 33-56, 1997.

DANELON, Maria Cristina T. de Moraes. As interações sociais de alunos com dificuldades de comunicação oral a partir da inserção de recurso da comunicação alternativa e ampliada associada aos procedimentos do ensino naturalístico. 2009. Tese (Doutorado em Educação) - Centro de Educação e Humanidades, Faculdade de Educação, Rio de Janeiro, 2009.

DELIBERATO, Débora. Habilidades expressivas de um aluno não falante com diferentes interlocutores. In: NUNES, Leila Regina D'Oliveira de Paula Pelosi; BONADIU, Myriam; GOMES, Márcia Regina. Um retrato da comunicação alternativa no Brasil: relatos de pesquisa e experiências. Rio de Janeiro: Quatro Pontos, FINEP, 2009. p. 137-142.

ELSABBAGH, Mayada et al. Global prevalence of autism and other pervasive developmental disorders. Autism Research, Hoboken, n. 5, p. 160-179, 11 abr. 2012.

FAGUNDES, Antônio. Descrição, definição e registro de comportamentos. São Paulo: Edicon, 1985.

GLENNEN, Sharon. Handbook of augmentative and alternative communication. London: Singular Publishing Group, 1992.

GOMES, Rosana Carvalho. Interações comunicativas entre uma professora e um aluno com transtorno invasivo do desenvolvimento na escola regular. 2011. 155 f. Dissertação (Mestrado em Educação) - Universidade Federal do Rio Grande do Norte, Natal, 2011.

HALL, Laura J. Autism Spectrum Disorders: from theory to practice. Upper Saddle River, NJ: Merrill Prentice Hall, 2012.

HEFLIN, Juane; ALAIMO, Donna Florino. Students with autism spectrum disorders: effective instructional practices. Upper Saddle River, N.J.: Pearson Prentice Hall, 2007.

KENNEDY, Craig H. Single-case designs for educational research. Boston: Pearson Education, Inc, 2005.

KLIN, Ami. Autismo e Síndrome de Asperger: uma visão geral. Revista Brasileira de Psiquiatria, v. 28, supl. 1, p. 3-11, 2006.

KUEHN, Bridget M. Autism spectrum disorders common. Journal of the American Medical Association, v. 297, p. 940, 2007.

LAMONICA, Dionísia A. C. Utilização de variações do ensino incidental para promover 0 aumento das habilidades linguísticas de uma criança diagnosticada autista. Temas em Psicologia, São Paulo, v. 1, n. 2, p. 127-130, 1993.

MACEDO, Elizeu Coutinho de; ORSATI, Fernanda. Comunicação alternativa. In: SCHWARTZMAN, José Salomão; ARAÚJO, Ceres Alves de. Transtornos do espectro do autismo. São Paulo: Memnon, 2011. p. 244-254.

MARTINS, Maria Rubia Rodrigues. Inclusão de alunos autistas no ensino regular: concepções e práticas pedagógicas de professores regentes. 2007. 159 f. Dissertação (Mestrado em Psicologia) - Universidade Católica de Brasília, 2007. 
MCGREGOR, Evelyn; CAMPBELL, Elaine. The attitudes of teachers in Scotland to the integration of children with autism into mainstream schools. Autism, v. 5 (2), p. 89-207, 2001.

NATIONAL AUTISM CENTER (Ed.). Evidence-based practice autism in the schools: a guide to providing appropriate interventions to students with autism spectrum disorders. 2. ed. Randolph, Massachusetts: National Autism Center, 2011. Disponível em: <http:// www.nationalautismcenter.org/pdf/NAC\%20Ed\%20Manual_FINAL.pdf>. Acesso em: 19 fev. 2013.

NUNES, Débora Regina de Paula. Efeitos dos procedimentos naturalísticos no processo de aquisição de linguagem através de sistema pictográfico de comunicação em criança autista. Dissertação (Mestrado em Educação) - Faculdade de Educação, Universidade do Estado do Rio de Janeiro, 2000.

. Autismo e inclusão: entre realidade e mito. In: MENDES, Enicéia Gonçalves; ALMEIDA, Maria Amélia (Orgs.). Dimensões pedagógicas nas práticas de inclusão escolar. 1. ed. Marília: Abpee, 2012, v. 2, p. 279-292.

Enhancing the use of augmentative communication systems of children with autism through caregiverimplemented naturalistic teaching strategies. Tese (Doctoral dissertation Florida State University) - Dissertation Abstracts International, 2005. Disponivel em: <http://etd. lib.fsu.edu/theses/available/etd-12062005-185208/>. Acesso em: 12 fev. 2010.

. AAC interventions for autism: a research summary. International Journal of Special Education. v. 23, p. 17-26, 2008.

FREIRE, Janielle; AZEVEDO, Mariana Orrico. Ampliando a comunicação de aluno com autismo: o professor enquanto agente de intervenção. In: DELIBERATO, Débora; GONÇALVES, Maria de Jesus; MACEDO, Elizeu Coutinho de. Comunicação alternativa: teoria, prática, tecnologias e pesquisa. São Paulo: Memmon Científicas, 2009. p. 115-131.

NUNES, Leila Regina de Paula. Métodos naturalísticos para o ensino da linguagem funcional em indivíduos com necessidades especiais. In: ALENCAR, Eunice Soriano de (Org.). Novas contribuições da psicologia aos processos de ensino e aprendizagem. São Paulo: Cortez, 1992.

OLIVEIRA, Anna Augusto Sampaio de. Representações sociais sobre educação especial e deficiência: 0 ponto de vista de alunos e professores. Tese (Doutorado em Educação) - Universidade Estadual Paulista, Marília/SP, 2002.

OLIVEIRA, Eloiza de; MACHADO, Katia da Silva. Adaptações curriculares: caminho para uma educação inclusiva. In: GLAT, Rosana. Educação inclusiva: cultura e cotidiano escolar. Rio de Janeiro: Sete Letras, 2007. p. 36-52.

PAULA Cristiane; RIBEIRO, Sabrina; FOMBONNE, Eric; MERCADANTE, Marcos. Brief report: prevalence of pervasive developmental disorder in Brazil. A pilot study. Journal of Autism and Developmental Disorders, 2011. p. 1200-1206.

PAULA, Kelly Maria Pereira de; NUNES, Leila Regina de Paula. A comunicação alternativa no contexto do ensino naturalístico. In: NUNES, Leila Regina de Paula. (Org.). Favorecendo o desenvolvimento da comunicação em crianças e jovens com necessidades educacionais especiais. Rio de Janeiro: Dunya, 2003. p. 95-109.

PAULA, Kely Maria Pereira de; ENUMO, Sônia Regina Fiorim. Avaliação assistida e comunicação alternativa: procedimentos para a educação inclusiva, Revista Brasileira de Educação Especial, Marília, v. 13, n. 1, Apr. 2007.

PEREIRA, Alessandra; RIESGO, Rudimar S.; WAGNER, Mario B. Autismo infantil: tradução e validação da Childhood Autism Rating Scale para uso no Brasil. J. Pediatr. Rio J. [online]. 2008, v. 84, n. 6, p. 487-494.

ROBERTSON, Kristen; CHAMBERLAIN, Brandt; KASARI, Connie. General education teachers' relationships with included students with autism. Journal of Autism and Developmental Disorders, 33, p. 123-130, 2003.

SERRA, Dayse Carla Genero. Entre a esperança e o limite: um estudo sobre a inclusão de alunos com autismo em classes regulares. Rio de Janeiro, 2008. 124p. Tese (Doutorado) - Departamento de Psicologia, Pontifícia Universidade Católica do Rio de Janeiro, Rio de Janeiro, 2008.

SHIRMER, Carolina R.; NUNES, Leila Regina de Paula. Perfil de alunos de pedagogia que estão freqüentando curso de formação inicial de professores para atuação na área de tecnologia assistiva com ênfase em comunicação alternativa e ampliada. SEMINÁRIO NACIONAL DE PESQUISA EM EDUCAÇÃO ESPECIAL, 5, São Paulo, Anais... São Paulo: AVPEE, 2009. 
SIMPSON, Richard. Evidence-based practices and students with autism spectrum disorders. Focus on Autism and Other Developmental Disabilities, v. 20, n. 3, p. 140-149, 2005.

SOUZA, Vera; Recursos alternativos para o desenvolvimento da comunicação. In: NUNES, Leila Regina. (Org.). Favorecendo o desenvolvimento da comunicação em crianças e jovens com necessidades educacionais especiais. Rio de Janeiro: Dunya. 2003. p. 219-233.

TANNOCK, Rosemary; GIROLAMETTO, Luigi. Reassessing parent-focused language intervention programs. In: WARREN, Steven F.; REICHLE, Joe (Eds). Causes and effects in communication and language intervention: communication and language intervention series. v. 1. Baltimore, MD: Paul H. Brookes Publishing, 1992. p. 49-79.

WALTER, Cátia; ALMEIDA, Maria Amélia. Avaliação de um programa de comunicação alternativa e ampliada para mães de adolescentes com autismo. Revista Brasileira de Educação Especial, Marília, v. 16, n. 3, dez. 2010.

WENDT, Oliver. Research on the use of graphic symbols and manual signs. In: MIRENDA, Pat; IACONO, Teresa (Eds.). Autism spectrum disorders and AAC. Baltimore: Paul H. Brookes, 2009. p. 83-137.

Recebido em: 25.09.2012

Aprovado em: 24.04.2013

Rosana Carvalho Gomes é professora da rede Estadual de Educação do Estado do Piauí e pedagoga na rede Municipal de Educação de Teresina-PI, pedagoga e mestre em Educação pela Universidade Federal do Rio Grande do Norte.

Débora R. P. Nunes é docente dos Programas de Graduação e Pós-Graduação em Educação da Universidade Federal do Rio Grande do Norte; doutora em Educação Especial pela Florida State University; Mestre em Educação pela Universidade do Estado do Rio de Janeiro; psicóloga pela Universidade Federal do Rio de Janeiro. 